Article

\title{
Integrating Imaging Spectrometer and Synthetic Aperture Radar Data for Estimating Wetland Vegetation Aboveground Biomass in Coastal Louisiana
}

\author{
Daniel Jensen ${ }^{1,2, * \mathbb{D}}$, Kyle C. Cavanaugh ${ }^{1}$, Marc Simard ${ }^{2}{ }^{\mathbb{D}}$, Gregory S. Okin ${ }^{1}$, \\ Edward Castañeda-Moya ${ }^{3,+}$, Annabeth McCall $^{3}$ and Robert R. Twilley ${ }^{3}$ \\ 1 Department of Geography, University of California at Los Angeles, Los Angeles, CA 90095, USA; \\ KCavanaugh@geog.ucla.edu (K.C.C.); okin@geog.ucla.edu (G.S.O.) \\ 2 Jet Propulsion Laboratory, California Institute of Technology, Pasadena, CA 91109, USA; \\ marc.simard@jpl.nasa.gov \\ 3 Department of Oceanography and Coastal Sciences, College of the Coast and Environment, Louisiana State \\ University, Baton Rouge, LA 70803, USA; edward.castaneda@fiu.edu (E.C.-M.); amcca24@lsu.edu (A.M.); \\ rtwilley@lsu.edu (R.R.T.) \\ * Correspondence: Daniel.J.Jensen@jpl.nasa.gov; Tel.: +1-562-972-3952 \\ + Present address: Southeast Environmental Research Center, Institute of Water and Environment, Florida \\ International University, Miami, FL 33199, USA.
}

Received: 30 August 2019; Accepted: 22 October 2019; Published: 29 October 2019

check for updates

\begin{abstract}
Aboveground biomass (AGB) plays a critical functional role in coastal wetland ecosystem stability, with high biomass vegetation contributing to organic matter production, sediment accretion potential, and the surface elevation's ability to keep pace with relative sea level rise. Many remote sensing studies have employed either imaging spectrometer or synthetic aperture radar (SAR) for AGB estimation in various environments for assessing ecosystem health and carbon storage. This study leverages airborne data from NASA's Airborne Visible/Infrared Imaging Spectrometer-Next Generation (AVIRIS-NG) and Uninhabited Aerial Vehicle Synthetic Aperture Radar (UAVSAR) to assess their unique capabilities in combination to estimate AGB in coastal deltaic wetlands. Here we develop AGB models for emergent herbaceous and forested wetland vegetation in coastal Louisiana. In addition to horizontally emitted, vertically received (HV) backscatter, SAR parameters are expressed by the Freeman-Durden polarimetric decomposition components representing volume and double-bounce scattering. The imaging spectrometer parameters include normalized difference vegetation index (NDVI), reflectance from 290 visible-shortwave infrared (VSWIR) bands, the first derivatives from those bands, or partial least squares (PLS) $x$-scores derived from those data. Model metrics and cross-validation indicate that the integrated models using the Freeman-Durden components and PLS $x$-scores improve AGB estimates for both wetland vegetation types. In our study domain over Louisiana's Wax Lake Delta (WLD), we estimated a mean herbaceous wetland AGB of 3.58 Megagrams/hectare (Mg/ha) and a total of $3551.31 \mathrm{Mg}$ over $9.92 \mathrm{~km}^{2}$, and a mean forested wetland AGB of $294.78 \mathrm{Mg} / \mathrm{ha}$ and a total of $27,499.14 \mathrm{Mg}$ over $0.93 \mathrm{~km}^{2}$. While the addition of SAR-derived values to imaging spectrometer data provides a nominal error decrease for herbaceous wetland AGB, this combination significantly improves forested wetland AGB prediction. This integrative approach is particularly effective in forested wetlands as canopy-level biochemical characteristics are captured by the imaging spectrometer in addition to the variable structural information measured by the SAR.
\end{abstract}


Keywords: aboveground biomass; deltaic wetlands; coastal Louisiana; imaging spectroscopy; hyperspectral; synthetic aperture radar (SAR); remote sensing; data integration; airborne visible/infrared imaging spectrometer-next generation (AVIRIS-NG); uninhabited aerial vehicle synthetic aperture radar (UAVSAR); blue carbon

\section{Introduction}

In coastal wetlands, as in other ecosystems, aboveground biomass (AGB) is an important indicator of vegetation health and productivity, as well as a key parameter for quantifying marsh response to sea level rise and resulting carbon storage loss. Vegetation biomass contributes to several ecosystem processes with feedbacks including nutrient allocation, sedimentation and accretion rates, riverine and tidal inundation, and weather patterns [1-4]. Estimation and monitoring of wetland biomass, or "blue carbon," are needed to assess a wetland's ability to trap exogenic sediment and produce organic soils that increase surface elevation relative to sea level rise [5,6]. Accurate AGB maps can be used to analyze and predict changes in wetland vegetation cover and total carbon storage $[2,7,8]$, and accordingly understand its impact on landscape and hydrological processes [9]. In addition to furthering our understanding of these processes, the observed spatial variability in biomass distributions can help support conservation and restoration efforts, making the research and development of optimized remote sensing methods critical [10].

Remote sensing data from satellite and airborne instruments, supported by in situ field measurements, offer the ability to develop empirical AGB models that can assess of ecosystem health and change $[4,5]$. These models depend on relationships between one or several remotely sensed parameters and AGB. Broadband multispectral data is the most widely distributed and utilized remote sensing data. With the ubiquity of multispectral satellite datasets, normalized difference vegetation index (NDVI), the normalized ratio of a pixel's near-infrared (NIR) and red reflectance that estimates plant photosynthetic activity [11], is the most commonly used optical variable for biomass mapping $[12,13]$. Beyond the level of canopy coverage affecting a pixel's radiance/reflectance signal, optical data does not easily provide information on plant structure. Different approaches employ synthetic aperture radar (SAR) data, as a radar signal's backscatter is sensitive to vegetation structure and thereby AGB [14]. There are often relationships between AGB and optical or radar backscatter variables, though the relationships are frequently logarithmic as parameters saturate at high biomass values $[4,12]$. Regression analysis provides the primary empirical tool for developing remote sensing-based data models that can be scaled to imagery and produce biomass maps. Multivariate regression analysis techniques can utilize the breadth of a sensor's spectral bands or combine data from multiple sensors to increase a model's predictive capability [5].

Imaging spectroscopy—or hyperspectral remote sensing—can leverage hundreds of contiguous narrow bands and complete spectral response for estimating AGB. Imaging spectrometer data can thus improve on existing methods or enable new ones. For example, narrow bands may be used to calculate indices with a more sensitive response for univariate regression [15], or multivariate techniques may be employed that utilize the continuous spectral data. A comprehensively measured visible-shortwave infrared (VSWIR) reflectance spectrum provides a powerful basis for estimating vegetation properties, as with canopy foliar traits and other environmental variables [16,17]. The spectral signature measured by the multitude of bands—either by an imaging spectrometer or an in situ field spectrometer [5] — can optimize predictive capability and disentangle a surface's spectral properties in relation to its AGB by emphasizing the spectral features that are most associated with canopy coverage, water content, and photosynthetic activity $[5,18]$. Utilizing the first derivative spectra, rather than reflectance or radiance, removes pixel brightness variability and further enhances spectral features which may in turn be correlated with AGB [19]. The resultant regression models will typically be more sensitive to those key spectral features' shapes and attain a higher coefficient of determination [5]. Imaging spectroscopy is 
thus potentially invaluable for attaining information on vegetation biochemical composition that can relate to biomass.

Synthetic aperture radar (SAR) is an active microwave instrument sensitive to structural information not contained within a plant's spectral signature. The scattering mechanisms and measured backscatter amplitudes can be used to make inferences of vegetation type, surface conditions, and structural characteristics-including AGB [20]. Among these frequently studied measures is leaf area index (LAI), which is often used as a measurement from which AGB can be estimated [21]. As several studies have demonstrated empirical relationships between LAI and various backscatter metrics [22-24], leaf abundance impacts SAR backscatter and contributes to AGB estimates. The primary SAR-based AGB estimation method typically involves conducting a regression analysis using cross-polarized horizontally emitted, vertically received (HV) data. HV backscatter measurements represent the response from volumetric scattering resulting from the radar signal's interaction with a vegetation canopy before returning to the sensor [14]. Other scattering mechanisms include surface scattering-the signal's specular reflection off a flat surface-and double bounce-where the signal is reflected by a surface onto a vertical object, effectively forming a right angle, scattering the signal towards the instrument $[14,25]$. A polarimetric decomposition estimate expresses the contribution of each of these three scattering mechanisms to the observed backscatter signal [26,27], and is useful for vegetation classification and AGB modeling [25].

There is great potential for developing accurate methods to estimate wetland AGB by integrating the biochemical data derived from imaging spectroscopy with the structural information provided by SAR $[13,28]$. Past studies have merged these datasets for forest AGB estimates, either directly with regression [29] or via leaf area index optimization [21]. Other studies use similar approaches with imaging spectroscopy and LiDAR, though they rely on band selection and so do not assimilate the full range of spectral information for model development [30,31]. This study examines the contribution of each remote sensing variable to both herbaceous and forested wetland AGB. Louisiana's Wax Lake Delta offers a valuable case study to estimate coastal wetland biomass estimation, as it is a prograding delta located within the greater Mississippi Deltaic Plain (MDP) where wetlands are severely degrading and receding [32,33] (Figure 1). Coastal Louisiana lost an estimated $4833 \mathrm{~km}^{2}$ of marsh area from 1932 to 2016 , accounting for roughly $25 \%$ of its coastal wetlands [34]. A better understanding of biomass stocks and distributions in these prograding deltaic wetland areas may inform future restoration efforts. AGB has been examined in the Wax Lake Delta (WLD), but as part of a broader national-scale assessment of carbon stocks using satellite data that did not resolve the local-scale AGB distributions in the WLD $[29,35]$ or as part of a regional-scale AGB assessment that could not find a robust relationship with available in situ and satellite data [6]. This study's primary objective, then, is to develop an integrated empirical approach for estimating AGB that leverages the unique capabilities provided by each data type collected in tandem by airborne instruments. In doing so, we interpret the contributions of different spectral features and radar scattering components to the AGB estimation, for both herbaceous and forested wetland vegetation. We then apply the models that attain optimal performance metrics, in both parameterization and cross-validation, to imaging spectrometer and SAR data collected over Louisiana's WLD (Figure 1). 


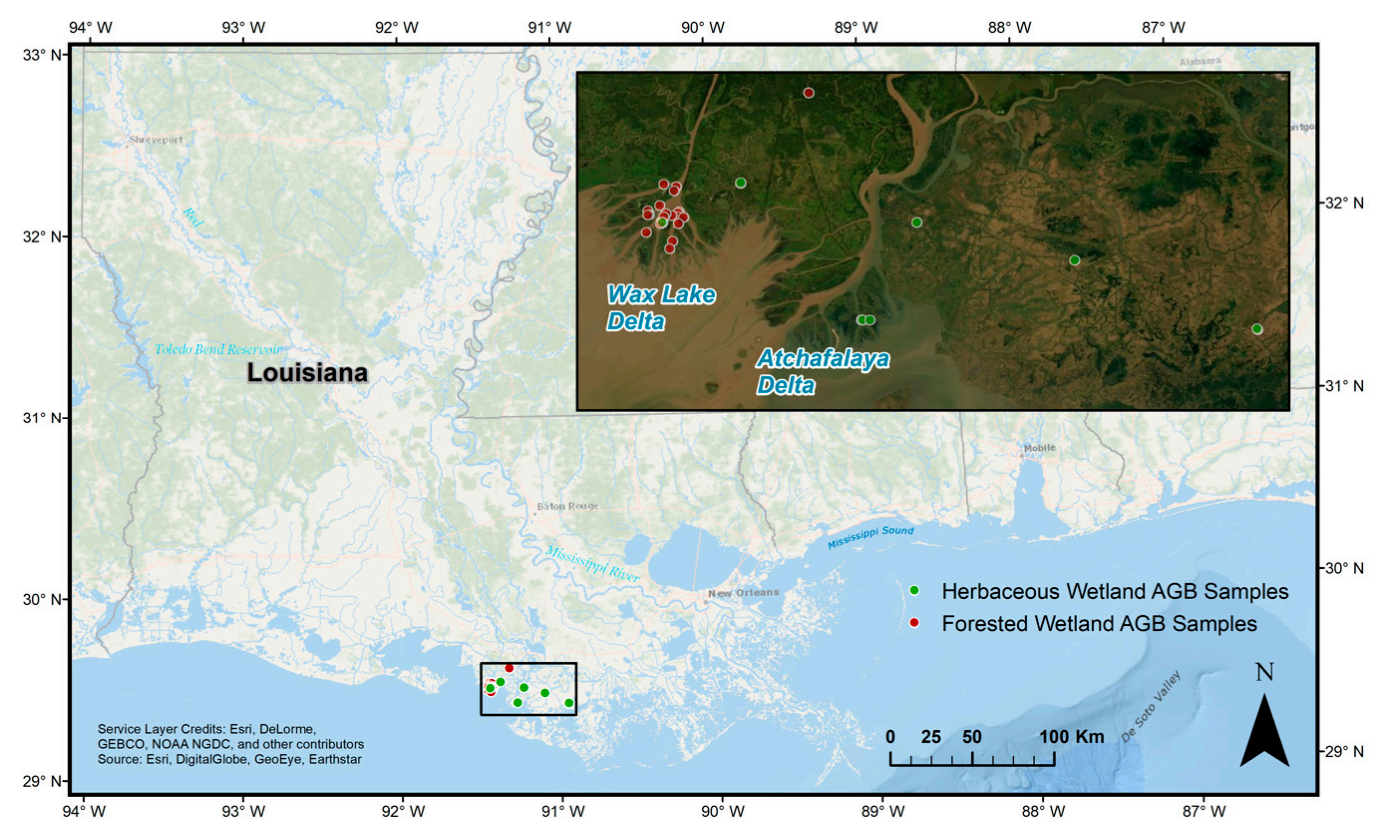

Figure 1. Study area for aboveground biomass sampling and airborne data collection. Sampling was focused on the Wax Lake Delta, with other sample sites in the Atchafalaya Delta and Terrebonne Basins to the east. Aboveground biomass (AGB) mapping was restricted to the Wax Lake Delta, though remote sensing measurements coincident with field plots extended beyond the delta for model calibration. Further AGB sample data and information is reported in Tables A1 and A2.

\section{Materials and Methods}

This study used airborne-derived reflectance spectra and SAR backscatter data, paired with coincident in situ AGB sample data, to develop and cross-validate a series of models based on one or both remote sensing datasets. The AGB data were primarily collected in the WLD, Louisiana, with other sample plots being located throughout the Atchafalaya and western Terrebonne Basins (Figure 1). The WLD is forming at the terminus of the Wax Lake Outlet, a constructed distributary channel of the Atchafalaya River, the main distributary of the Mississippi River. The outlet was constructed in 1942, diverting flow from the lower Atchafalaya River to alleviate flooding in the Morgan City area [36]. Whereas the basins east of the Wax Lake Outlet and Atchafalaya River are severely degrading and seeing widespread wetland submergence, the WLD is an actively prograding system with accretion-driven feedbacks creating emergent deltaic floodplains [32]. Areal land growth rates in the WLD range between $1-3 \mathrm{~km}^{2} /$ year [37]. As this artificial outlet has been allowed to build land under natural hydrologic conditions, the WLD presents an ideal case study for potential river diversion projects aimed at alleviating wetland subsidence and degradation across Louisiana's coast [33].

\subsection{Field Data}

Biomass field surveys were conducted in 2015 and 2016 to spatially coincide with imagery collected over multiple flight campaigns. Two field campaigns were conducted-one in May of 2015 and one in November of 2016 - to encompass a range of biomass values across the growing season, where September is considered the peak biomass season. Fifteen sites coinciding with the May and June 2015 flight-lines (Table 1) were examined in the 2015 collections, six of which were forested wetlands and nine herbaceous. Eight of the fifteen sites were located in the Wax Lake/Atchafalaya delta complex, while seven were selected in the western Terrebonne Basin. Ten out of the fifteen selected sites are part of Louisiana's Coastwide Reference Monitoring System (CRMS) [38]. One site within the WLD was examined on 15 November 2016, solely for herbaceous wetland samples coinciding with the 17 October 2016, flightlines. 
For the forested wetland sites (Figure 1, Table A2), which were only examined in May 2015 given the small expected changes in annual tree growth and biomass, duplicate circular plots (10 $\mathrm{m}$ radius, $50 \mathrm{~m}$ apart) were established inside the forest approximately $30 \mathrm{~m}$ from the forest edge. Plots not located at CRMS sites were chosen for their accessibility within the WLD and representativeness of the immediate area. All trees with diameter at breast height $(\mathrm{dbh}, 1.3 \mathrm{~m}) \geq 2.5 \mathrm{~cm}$ were measured within each plot. Species type were also registered, with Salix nigra being the predominant species in most plots. The height of all trees was measured with a laser range finder (Impulse 200 LR, Laser Technology Inc., Tucson, WY) and species-specific allometric equations [39-41] were applied to estimate dry AGB. Thirty-six individual forested wetland plots within the six examined sites coincided with airborne flight-lines and were used in this study.

At herbaceous wetland sites (Figure 1, Table A1), AGB was harvested inside duplicate plots $\left(0.25 \mathrm{~m}^{2}, 5 \mathrm{~m}\right.$ apart $)$ at 10,50 , and $100 \mathrm{~m}$ along a transect established perpendicular to the wetland edge. The aboveground material in each plot was clipped at soil level, stored in plastic bags, refrigerated at $4{ }^{\circ} \mathrm{C}$, and transported to the laboratory for further processing. Fresh plant material was sorted by species and dried at $60^{\circ} \mathrm{C}$ for $72 \mathrm{~h}$ before weighing to attain dry AGB $\left(\mathrm{g} / \mathrm{m}^{2}\right)$. It should be noted that two of the 2016 plots were $0.49 \mathrm{~m}^{2}$ and three were $0.75 \mathrm{~m}^{2}$, and that two plot pairs coincided with the same pixel and were averaged together. In total, 25 herbaceous plots coinciding with airborne flight-lines were utilized for this study, with fifteen plots collected in May 2015 and ten in November 2016.

\subsection{Remote Sensing Data}

\subsubsection{Imaging Spectrometer Data}

The Airborne Visible-Infrared Imaging Spectrometer-Next Generation (AVIRIS-NG) instrument measures 14-bit radiance from 380 to $2510 \mathrm{~nm}$ wavelengths with a $\sim 5 \mathrm{~nm}$ spectral resolution (Table 1) [42,43]. AVIRIS-NG conducted five flight-lines over the WLD on 17 October 2016, producing individual datasets with 425 bands at a $5.4 \mathrm{~m}$ spatial resolution. These flight-lines provided the basis for mapping AGB, though we processed additional flight-lines from May and June, 2015, in order to extract pixel spectra coincident with field plots. Each raw dataset was atmospherically corrected using the physics-based Atmospheric removal (ATREM) algorithm to derive a surface reflectance image [43-45]. We applied the Adaptive Reflectance Geometric Correction (ARGC) algorithm to correct bidirectional reflectance distribution (BRDF) effects that cause across-track variations in observed illumination intensity [46]. With spectrally consistent surface reflectance data post-correction, we mosaicked the 2016 flight-lines and subset the resulting dataset to the WLD's extent (Figure 2).

Table 1. Airborne remote sensing instrument information.

\begin{tabular}{|c|c|c|}
\hline & $\begin{array}{l}\text { Airborne Visible/Infrared } \\
\text { Imaging Spectrometer-Next } \\
\text { Generation (AVIRIS-NG) }\end{array}$ & $\begin{array}{c}\text { Uninhabited Airborne Vehicle } \\
\text { Synthetic Aperture Radar } \\
\text { (UAVSAR) }\end{array}$ \\
\hline Acquisition Dates & $\begin{array}{l}17 \text { October } 2016 \text { (Mosaic, Figure 2); } \\
\text { 6-9 May 2015; 2-6 June } 2015\end{array}$ & $\begin{array}{c}17 \text { October } 2016 \text { (Mosaic, Figure 3); } \\
9 \text { May } 2015\end{array}$ \\
\hline Aircraft Platform & B200 King Air & Gulfstream-III \\
\hline Wavelength/Frequency & $\begin{array}{c}380-2510 \mathrm{~nm} \\
\text { (Passive Radiance Measurements) }\end{array}$ & $\begin{array}{c}\text { Fully polarimetric L-band; } \\
0.2379 \mathrm{~m} / 1.26 \mathrm{GHz} \\
\text { (Transmitted Frequency) }\end{array}$ \\
\hline Spectral Resolution & $5 \mathrm{~nm} \pm 0.5 \mathrm{~nm}$ & $\begin{array}{c}80 \mathrm{MHz} \\
\text { (Chirp Bandwidth) }\end{array}$ \\
\hline Spatial Resolution & $5.4 \mathrm{~m}$ & $5 \mathrm{~m}$ \\
\hline Direct Model Inputs & Reflectance & $\begin{array}{l}\text { Horizontally-Transmitted, } \\
\text { Vertically-Received Backscatter }\end{array}$ \\
\hline Derived Model Inputs & $\begin{array}{l}\text { NDVI; } \\
\text { First-Derivative of Reflectance }\end{array}$ & $\begin{array}{l}\text { Volume and Double Bounce } \\
\text { Scattering Components }\end{array}$ \\
\hline
\end{tabular}




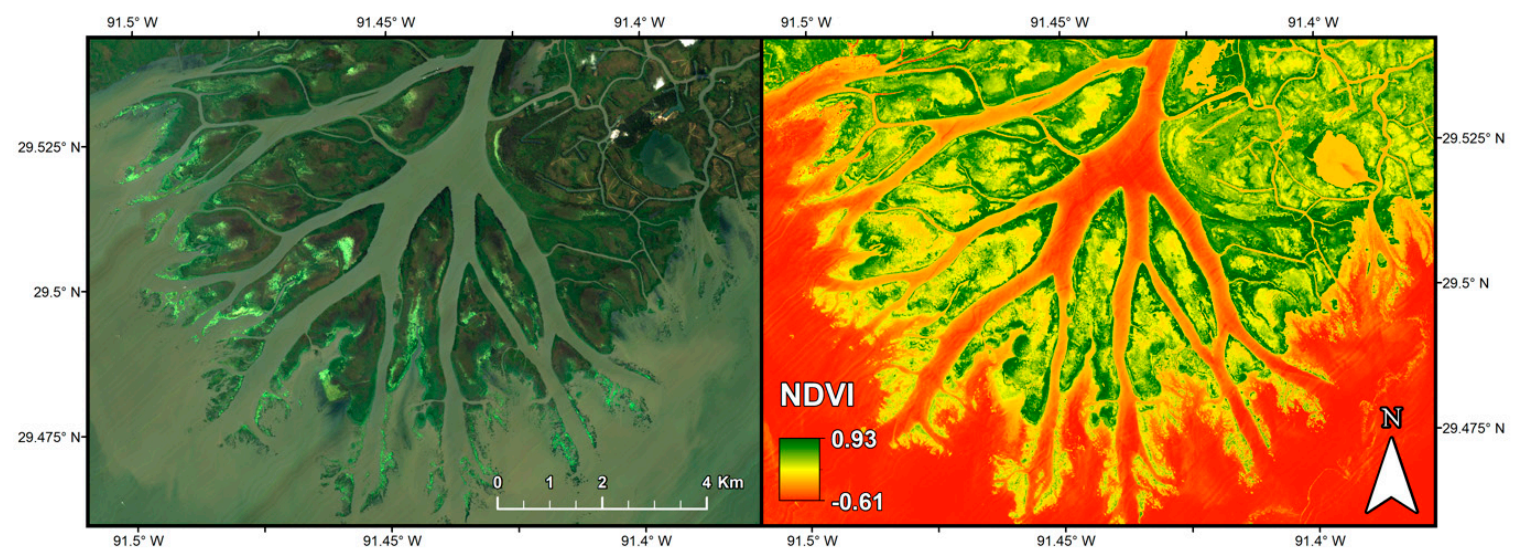

Figure 2. (Left) True color composite of the Airborne Visible-Infrared Imaging Spectrometer-Next Generation (AVIRIS-NG) mosaic over the Wax Lake Delta (WLD), and (Right) normalized difference vegetation index (NDVI) calculated from AVIRIS-NG bands centered at 671.95 and $757.10 \mathrm{~nm}$.

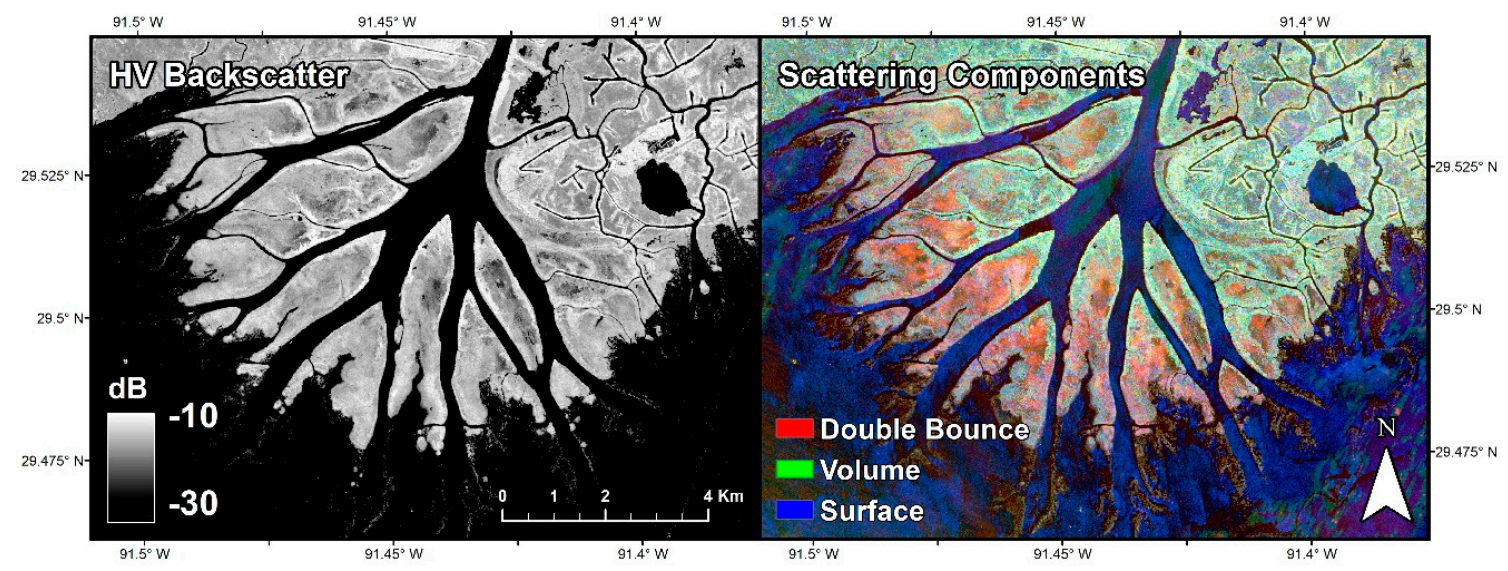

Figure 3. (Left) Horizontally emitted, vertically received (HV) backscatter image of the 2016 Uninhabited Airborne Vehicle Synthetic Aperture Radar (UAVSAR) data over the WLD, and (Right) false color composite of the volume, double bounce, and surface scattering components from the Freeman-Durden polarimetric decomposition.

\subsubsection{Synthetic Aperture Radar Data}

NASA's L-band Uninhabited Airborne Vehicle Synthetic Aperture Radar (UAVSAR) was flown concurrently with AVIRIS-NG in May 2015 and October 2016 (Table 1). The 2016 data, with 5 m posting, was subset to the WLD mosaic's extent and resampled to $5.4 \mathrm{~m}$ resolution (Figure 3). The SAR signal results from different scattering mechanisms as the emitted microwaves interact with a vegetation canopy and surface before partially returning to the sensor $[13,14]$. The radar signal's HV backscatter amplitude is dominated by volume scattering and has been shown to be the polarization most sensitive to AGB estimation $[28,47,48]$.

\subsection{Model Development}

For each field measurement, we extracted the coincident AVIRIS-NG and UAVSAR pixel values. These data entailed surface reflectance measurements from AVIRIS-NG in addition to HV backscatter and scattering component values. These various measurements provided the basis of our modeling approach, whereby we assessed the efficacy of commonly applied univariate approaches, multivariate approaches from a single sensor, and new multivariate approaches that integrate both sensors. It should be noted that the herbaceous samples did not include submerged aquatic vegetation (SAV) or floating vegetation, which comprise a large portion of the low intertidal and subtidal zones. These types were excised from the final mapped area, as the spectral signal from SAV is impacted by water while 
floating vegetation is too transient and spectrally variable for an accurate AGB prediction. For example, Nelumbo lutea is an emergent floating leaf vegetation that dominates the transition zone between submersed aquatic to emergent vegetation, and it is actively senescing at the time of image capture. Assessment and cross-validation of the models consequently reveals the optimal models to apply to the imagery and map AGB across the WLD.

\subsubsection{Single Sensor Ordinary Least Squares Regression Models}

Univariate regression based on a reflectance band, spectral index, or radar backscatter signal is the most common approach for remote AGB estimates $[13,28,49,50]$. This is typically done by fitting a linear, logarithmic, or other polynomial function to the in situ AGB data and the paired remotely sensed value using ordinary least squares regression (OLSR), though machine learning algorithms are increasingly prevalent [29]. Normalized difference vegetation index (NDVI), being sensitive to vegetation's chlorophyll content and health, is the most frequently applied optical index for AGB estimation. To this end, many studies have shown NDVI to be the most effectively predictive optical index $[13,49]$. While many studies employ NDVI such that the index values correspond to a single field collection [18], NDVI is often applied with several field collections for empirical AGB models such that it captures seasonal biomass variations [49], Without a full seasonal dataset, NDVI may show a significant relationship with AGB if the study area contains sufficient variance in plant tissue abundance and surface conditions [13]. However, these measurements may be hampered by the tendency of NDVI to saturate beyond a certain LAI [18] or in areas where soil and water may strongly influence the reflectance signal [13]. To test the index's efficacy in relation to other approaches and data types for AGB estimation, we generated NDVI values with red and near-infrared (NIR) AVIRIS-NG bands centered at 671.95 and $757.10 \mathrm{~nm}$, respectively. These are the closest AVIRIS-NG bands that correspond to the optimal wavelengths for calculating narrow-band NDVI denoted by Elvidge and Chen [15]. We then fit a linear OLS model to the resulting NDVI values and the AGB data to test whether an optical index-based approach was sufficient for estimating biomass in the spectrally and spatially complex WLD.

We implemented a similar approach with the UAVSAR imagery, whereby we fit a linear OLSR model to the HV backscatter data [48]. Additionally, we decomposed the radar signal into the contributions of its constituent scattering mechanisms-volume, double bounce, and surface scattering - to provide a more comprehensive description of a plant area's structural properties, and thus biomass [25,50]. We applied the Freeman-Durden polarimetric decomposition [51] to the UAVSAR data, producing the various scattering mechanism contributions to the observed backscatter signal (Figure 3). Because the surface component contains excessive noise and is not significantly impacted by vegetation structure [25], it was not included in subsequent AGB models. Conversely, volume scattering is largely associated with attenuation and multiple reflection within vegetation canopies. The volume scattering component in the Freeman-Durden decomposition is approximated by $\mathrm{HV}$ backscatter [51]. Further, corner reflection resulting from surface-trunk interaction contributes to double bounce scattering $[25,52]$. Using the volume and double bounce components, we developed bivariate OLSR models for both herbaceous and forest vegetation.

\subsubsection{Imaging Spectrometer Partial Least Squares Regression Models}

Partial least squares regression (PLSR) provides a suitable tool for leveraging the full breadth of imaging spectrometer data, as it does not rely on the statistical assumption of independence among input variables that OLSR does [53]. PLSR is instead focused on maximizing predictive capabilities, though it is prone to model overfitting [16]. As derivative spectroscopy has proven effective for hyperspectral AGB models [5], the first derivative of reflectance was also calculated for each sample. We generated PLSR models for AGB separately for herbaceous and forest vegetation, based on both reflectances and derivatives to test the relative performance of each type. We subsequently examined the spectral characteristics each model is sensitive to. 
For these reflectance and derivative models, we applied 290 of the original 425 AVIRIS-NG bands. We excised bands within the 376.44-441.55, 892.33-942.42, 1107.71-1157.79, 1353.13-1488.36, 1783.88-2024.29, and 2404.95-2500.12 nm spectral regions due to atmospheric water vapor interference. With the input spectra processed, further analysis was required to determine the PLSR models' optimal number of components. PLS components, also referred to as latent variables, are the synthetic variables in n-space that the input independent variables are projected onto. These are akin to principal components used in principal components analysis (PCA), though PLS components are developed with a weighting for the dependent variable's response [54,55]. The PLS transformations of both the reflectance and derivative AVIRIS-NG data are shown in Figure 7. We then calculated the predicted residual sum of squares (PRESS) statistic for 1-15 components (Figure 4). Calculating PRESS employs leave-one-out cross validation, whereby the model with the minimum summed value denotes the optimal number of components [16,56,57]. For the reflectance models, four and three components were selected for the forest and herbaceous models, respectively. It should be noted that the one-component PRESS statistic was slightly lower for the herbaceous reflectance models, though the model's $R^{2}(0.23)$ and mean absolute error (MAE) (103.41) were significantly inferior to the selected three-component model. Two components produced the lowest PRESS for both derivative-based models.

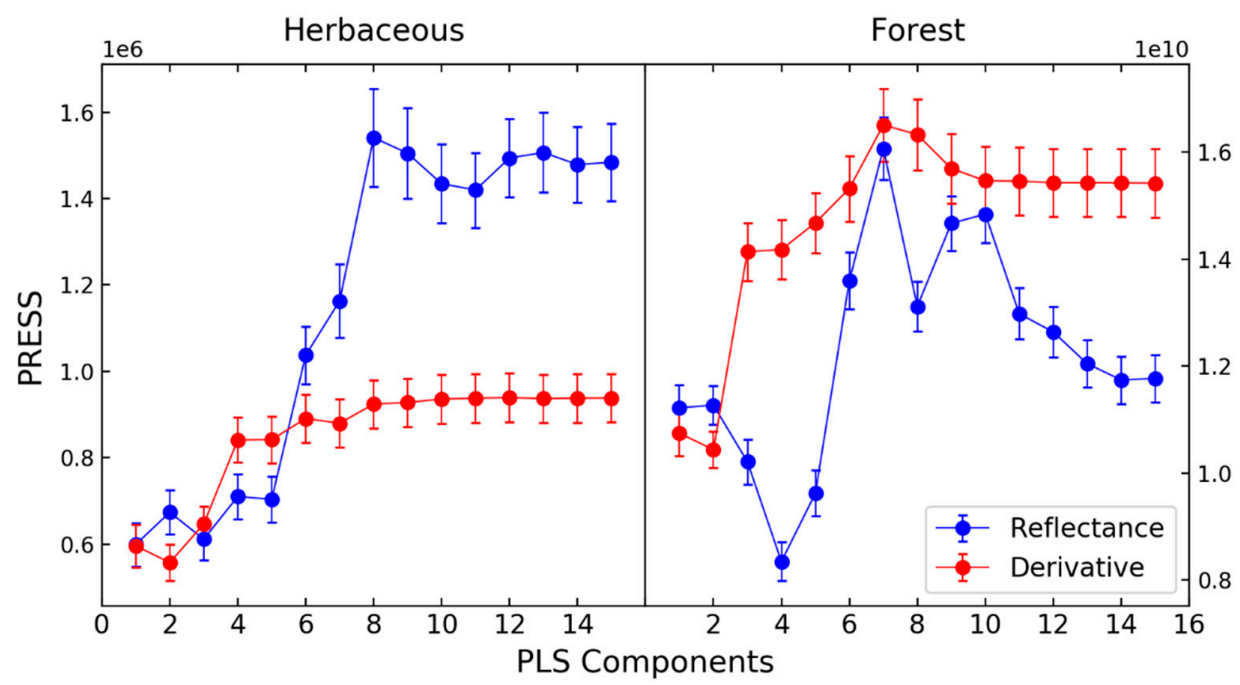

Figure 4. Predicted residual sum of squares (PRESS) statistic, calculated for 1-15 components for both reflectance and first-derivative-based models for herbaceous and forested wetlands. Error bars denote one standard deviation.

The variable importance in the projection (VIP) metric highlights the spectral domains that have the greatest bearing on the dependent variable $[53,54]$. When applied to imaging spectrometer-derivative data, the VIP response has the advantage of identifying narrow spectral features associated with the dependent variable [58]. We calculate VIP for both the herbaceous and forest derivative-based PLSR models using Equation (1):

$$
V I P_{i}=\sqrt{p \sum_{a=1}^{A}\left[\left(q_{a}^{2} t^{\prime}{ }_{a} t_{a}\right)\left(w_{a i} /\left\|w_{a}\right\|\right)^{2}\right] / \sum_{a=1}^{A}\left(q_{a}^{2} t^{\prime}{ }_{a} t_{a}\right)},
$$

where $\mathrm{p}$ is the X-loading, $\mathrm{q}_{\mathrm{a}}$ is component $a^{\prime} \mathrm{s}$ Y-loading, $\mathrm{t}_{\mathrm{a}}$ is its score vector, and $\mathrm{w}_{\mathrm{a}}$ is its loading weight. The loading $\left(\mathrm{w}_{\mathrm{ai}} /\left\|\mathrm{w}_{\mathrm{a}}\right\|\right)^{2}$ represents the importance of variable $i$ and explains the variance in each PLS component. The VIP $\mathrm{V}_{i}$ weights thus measure the contribution of each variable according to that variance. We applied a moving average to smooth the VIP responses and clearly define spectral features where VIP $>1$, denoting significant predictive power (Figures 5 and 6). By highlighting the specific spectral regions that increase predictive power, VIP aids in interpreting the biophysical 
Remote Sens. 2019, 11, 2533

9 of 24

characteristics that drive each PLSR model. Additionally, the biophysical information associated with each component for the different models can viewed spatially by applying the PLS transformation to the AVIRIS-NG data (Figure 7).

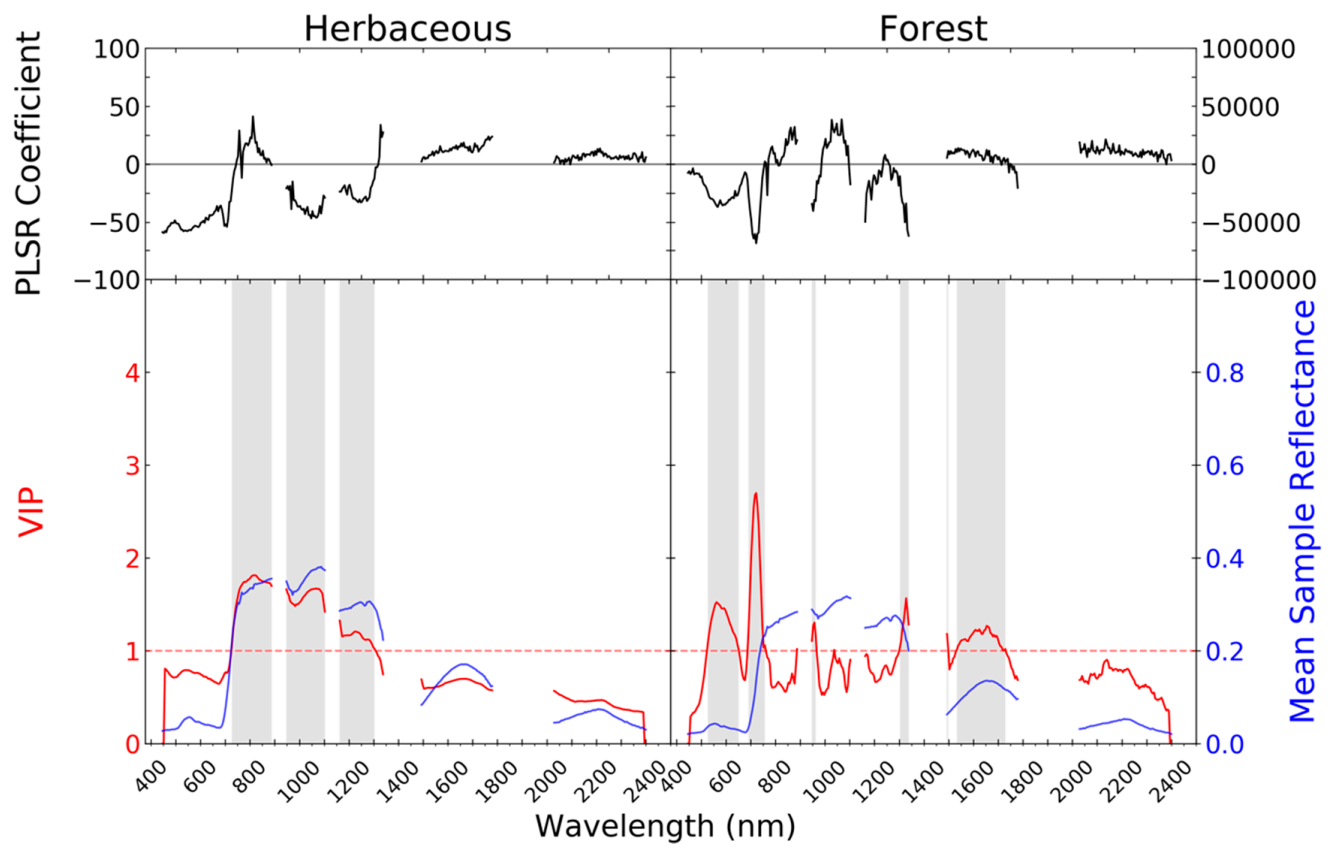

Figure 5. Reflectance-based partial least squares regression (PLSR) model results, corresponding to Model 2 in Table 4. The model coefficients for each band are shown in black in the top panels. In the bottom panels, variable importance in the projection (VIP) values are shown in red while average sample reflectance for either vegetation type is shown in blue. Spectral regions where VIP $>1$ are highlighted in gray. Mean sample reflectance is calculated from the pixel values corresponding with each in situ plot and provides a reference for interpreting variable importance based on how the VIP signal aligns with spectral characteristics.

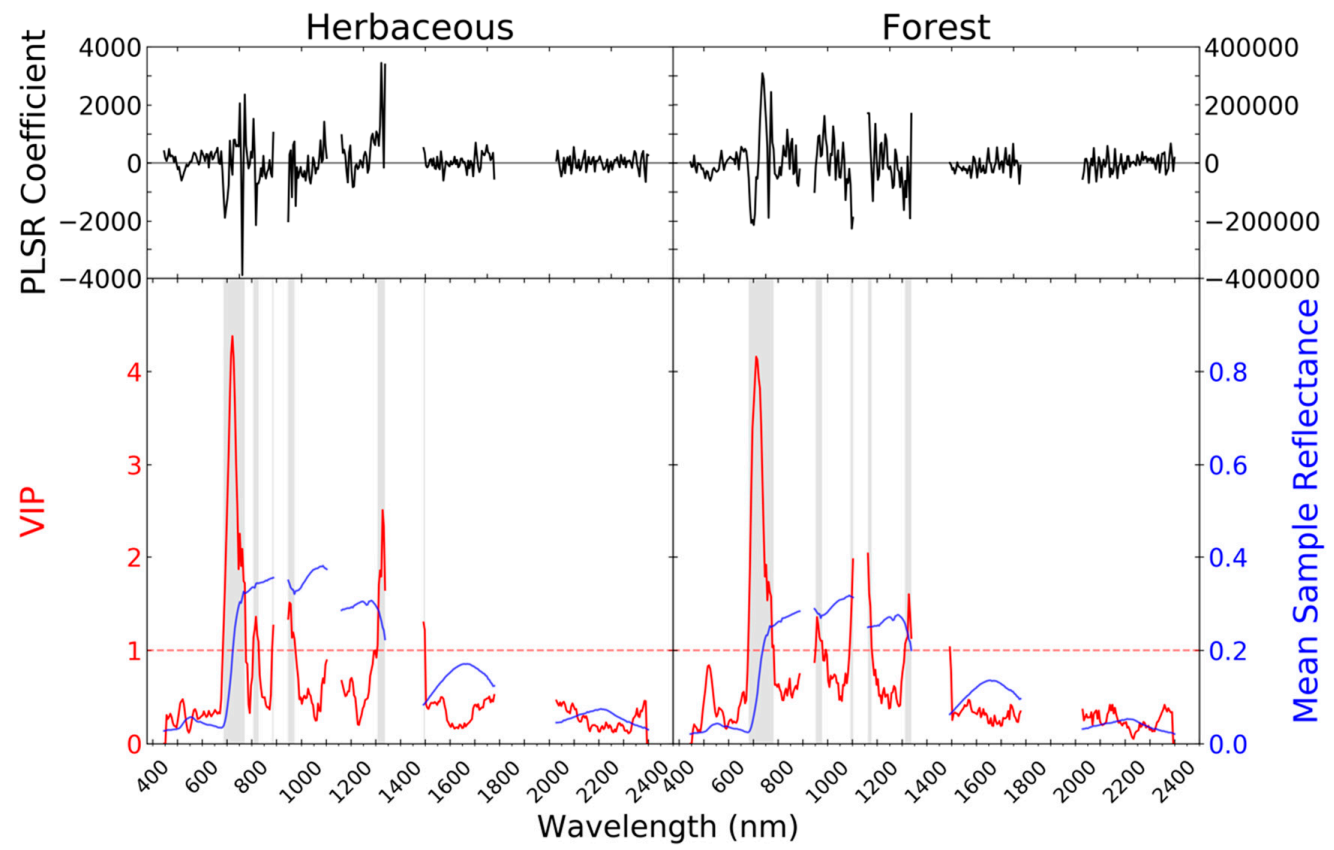

Figure 6. Derivative-based PLSR model results, corresponding to model 3 in Table 4. 
(a) Forested Wetland AGB - Reflectance PLS Components

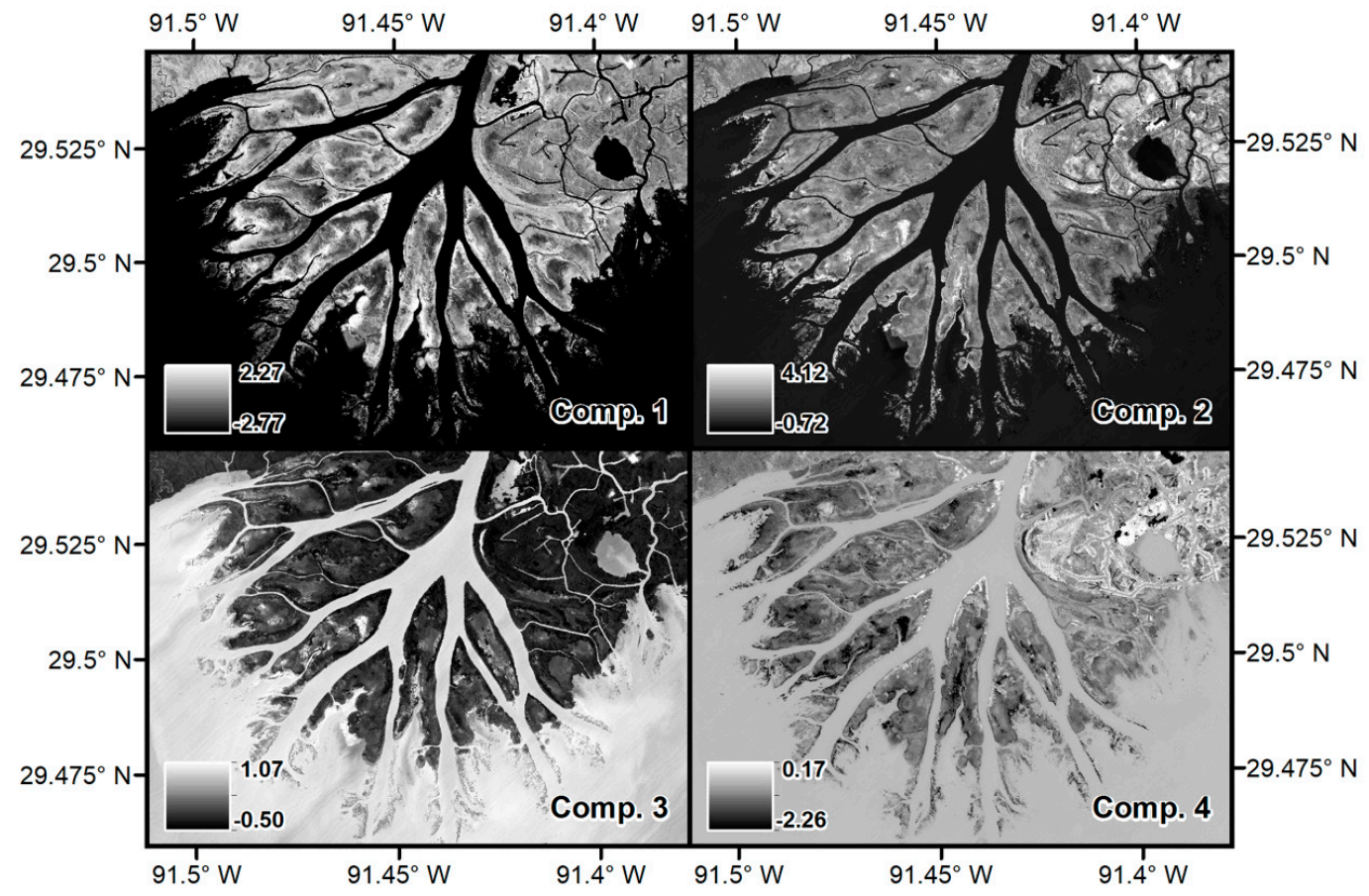

\section{(b) Herbaceous Wetland AGB - Derivative PLS Components}

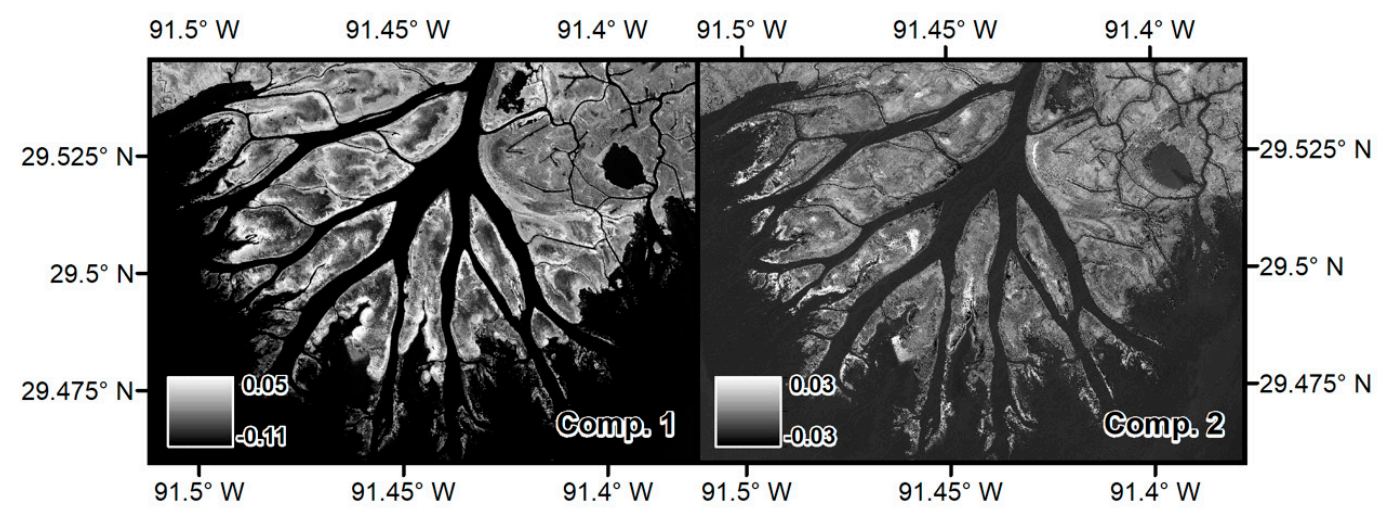

Figure 7. (a) The four component responses for the PLS transformation based on the forested wetland biomass and AVIRIS-NG reflectance, and (b) the two component responses for the PLS transformation based on the herbaceous wetland biomass and AVIRIS-NG first derivative of reflectance. The greyscale and legends indicate the component loading values.

\subsubsection{Integrated Multi-Sensor Models}

To determine if imaging spectrometer and SAR data beneficially complement each other for AGB estimation, we applied different variable combinations to develop optimized models integrating both datasets. We first combined the NDVI data with both the HV backscatter and the Freeman-Durden scattering components together. This allowed us to examine if a simple and easily calculable optical metric of vegetation health adds complementary information to the physical structural information provided by SAR data. However, the PLSR model inputs cannot be similarly combined with the SAR values to increase model efficacy, as we observed that the one or two extra parameters significantly degrade model results by giving inordinately high weight to the SAR variables and diminishing the spectral data's contribution. Other studies employing imaging spectroscopy for integrative AGB 
models rely on VIP analysis for band selection, rather than just interpretation, and so lose other bands' contributions to the AGB estimates by excising them from the final model [30,31]. To assimilate the full range of VSWIR spectral information provided by imaging spectrometers into this approach, the PLSR approach must be adapted.

To modify the approach and fully integrate the two remotely sensed datasets, we extracted the PLS x-scores associated with each component-also referred to as factors [16], latent variables or vectors [54,55], or bases [59] — from each model [60]. These represent the normalized scores for the dimensionally reduced training data before each training variable is weighted with respect to the dependent variable to calculate the component loadings [53,54,61]. Using PLS x-scores instead of PCA loading values offers more predictive capability, as the PLS components are constructed by taking information from both the independent and dependent variables into account [60]. Obtaining the $x$-scores from the PLS decomposition and applying them separately in a regression to predict a dependent variable provides flexibility in using PLS to optimally extract orthogonal components from the independent variable dataset while avoiding restriction to the original PLS model [60]. In doing so, the entire spectrum - for either reflectance or its derivative-associated with each AGB entry is reduced to statistically independent variables suited for combination with other data. The reflectance models were thus processed to calculate three PLS x-score values for herbaceous vegetation and four for the forested wetland models, while the derivative models used two PLS x-scores each. The $x$-scores were then combined with either the HV backscatter or the paired volume and double bounce scattering values.

Our analysis resulted in a suite of models of varying complexity, each of which indicates the relative quality and importance of each input type in relation to the other variables. Uncertainty in each model was characterized by applying a leave-one-out cross validation, whereby we plotted the distribution of errors and calculated the MAE for each model. The cross-validation distribution of errors and MAE complement the model performance metrics based on calibration with all available data. The models that attained the lowest MAE, for both the initial model statistics and cross-validation, were applied to the AVIRIS-NG and UAVSAR imagery to map AGB over the Wax Lake Delta.

A classification (Figure 8) map was created to apply these models to their appropriate corresponding pixels. We first employed PCA to transform the 290 AVIRIS-NG reflectance bands into nine principle component bands. We then combined these bands with a LiDAR-based digital elevation model of the WLD [62] and applied an ISODATA unsupervised classification. We combined the resulting classes to reflect forested wetland vegetation, herbaceous wetland vegetation, other vegetation, and water. The other vegetation class includes SAV, N. lutea, and other floating vegetation types that are not suitable for the herbaceous AGB model's application. The extent of the classification map and the WLD's boundaries reflect those employed by a 2011 vegetation map [63] for consistency with established datasets. We conducted a validation survey on October 26, 2018, collecting 143 in situ observations along seven transects that crossed different vegetation types. With these points, we generated a confusion matrix (Table 2) and individual class accuracies, calculating an overall map accuracy of $95.10 \%$ (Table 3).

Table 2. Classification confusion matrix.

\begin{tabular}{ccccc}
\hline $\begin{array}{c}\text { Classification } \\
\text { Data }\end{array}$ & Forested Wetland & $\begin{array}{c}\text { Reference Data } \\
\text { Herbaceous Wetland }\end{array}$ & Other Vegetation & All \\
\hline Forested wetland & 21 & 0 & 0 & 21 \\
Herbaceous wetland & 1 & 67 & 0 & 68 \\
Other vegetation & 0 & 6 & 48 & 54 \\
All & 22 & 73 & 48 & 143 \\
\hline
\end{tabular}


Table 3. Classification accuracy statistics.

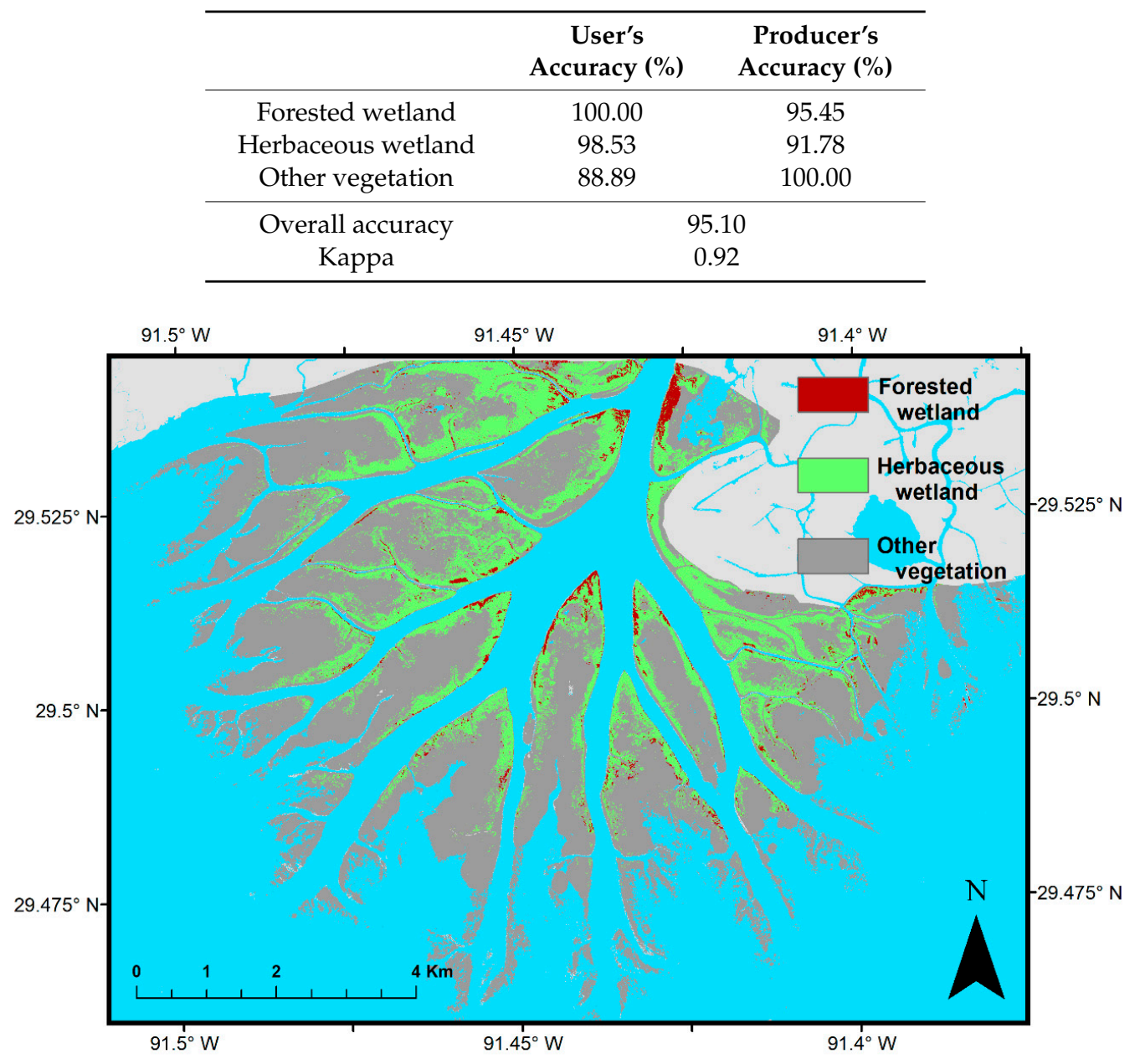

Figure 8. Classification map used to apply the forested and herbaceous wetland AGB models. The "other vegetation" class includes Nelumbo lutea, floating vegetation, and submerged aquatic vegetation (SAV) and was excluded from model application.

\section{Results}

All models and their corresponding numerical designation are reported in Table 4. The single sensor OLSR models (models 1 and 4) did not produce suitable AGB predictions, with the exception of the forest volume and double bounce scattering model (model 5) (Table 4). Adding NDVI to either the HV backscatter (model 6) or volume and double bounce model (model 7) only marginally increased model performances. These models did not attain appropriately low significance values, assuming a standard threshold of $\mathrm{p}<0.05$, for herbaceous vegetation. For the forest models, though the NDVI coupled with the Freeman-Durden components does attain a significant p-value, the performance metrics are similar to the volume and double bounce-only model.

The models that employ the full spectral response via PLS (models 2 and 3) attain superior performance metrics compared to the other models. For herbaceous vegetation, the first derivative PLSR model based only on AVIRIS-NG data performed significantly better than its reflectance counterpart. This is counter to the forest results, where the reflectance PLSR model is superior. All PLSR models, though, show high RMSE values relative to their MAEs, meaning the models do not perform well at higher AGB values. Combining the resultant PLS x-scores with the UAVSAR-derived values yields marked increases in model performance. The herbaceous models show a minor increase in $\mathrm{R}^{2}$ from the standard PLSR approach when adding HV backscatter to the derivative PLS $\mathrm{x}$-scores (model 9), with the Freeman-Durden components additionally producing similar results (model 11). 
The forest models show a more significant increase in performance when integrating the SAR data with the reflectance PLS x-scores. While adding the HV data to the PLS x-scores (model 8) yields similar results to the PLSR models themselves, adding the volume and double bounce scattering component data (model 10) significantly increases model $\mathrm{R}^{2}$ and decreases error.

Cross-validation of these models corroborates the compiled model performance metrics. The leave-one-out cross validation approach produced a series of error values for each model, shown as boxplot distributions in Figure 9. We averaged the errors for each model to calculate validation MAE values, reported in Table 5. The combined PLS and Freeman-Durden components models-using derivatives for herbaceous (model 11) and reflectance for forest vegetation (model 10)_produce the lowest MAE in the validation. Of the OLS models, though, model 9 attains the lowest Akaike Information Criterion (AIC) for herbaceous vegetation. Models 10 and 11 attain the lowest AIC for forested vegetation. AIC penalizes the use of additional variables to avoid overfitting, indicating the potential benefit of including extra information relative to the error reduction. Model coefficient and constant values are reported in Table A3. With the use of the PLS x-scores and Freeman-Durden components, these results reveal a marginal improvement in herbaceous AGB estimation error relative to the other models, but a substantial error reduction for forest AGB.

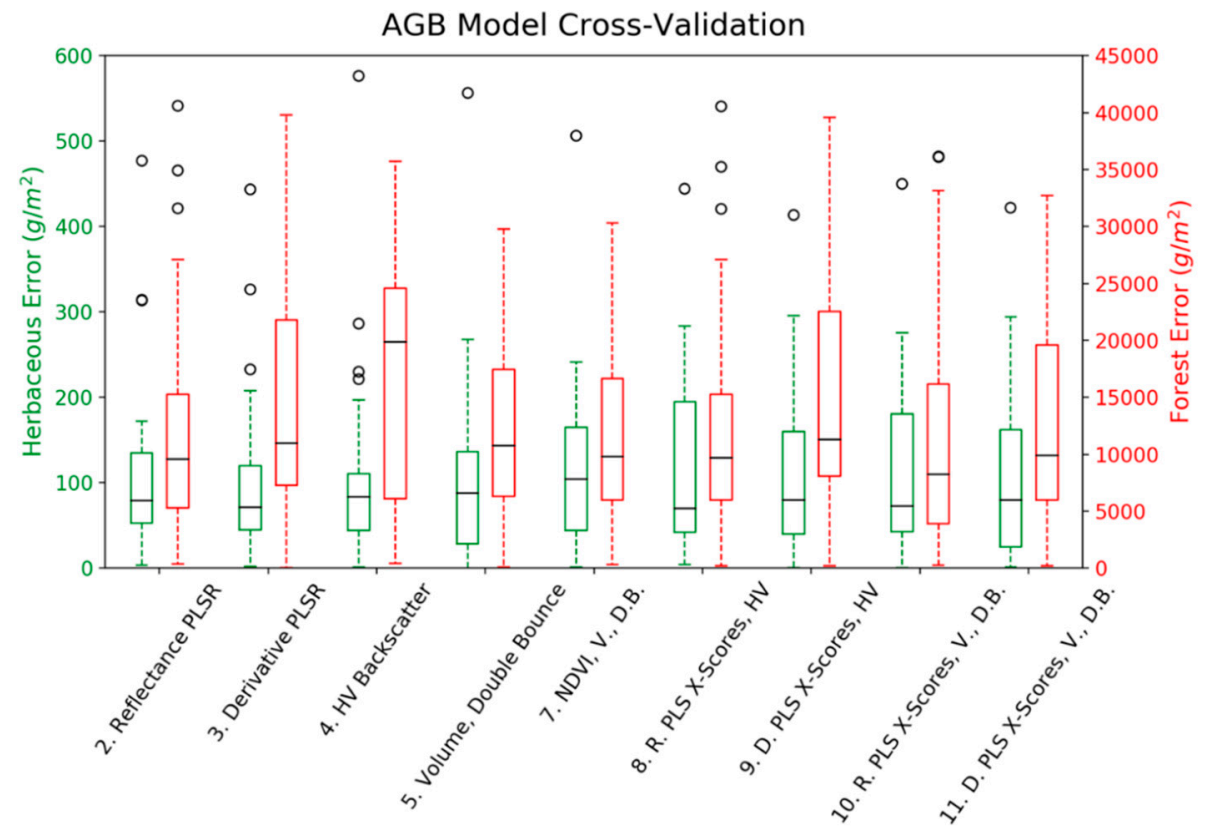

Figure 9. Distribution of leave-one-out cross-validation errors for the applicable herbaceous and forest AGB models. The circles, or "fliers," represent outliers. Models 1 (NDVI) and 6 (NDVI, HV Backscatter) are excluded as performance was not significant $(\mathrm{p}<0.05)$ for either herbaceous or forested vegetation.

As the models applying PLS x-scores with the Freeman-Durden components (models 10 and 11) yielded the lowest MAEs for both the overall model using all available data (Table 4) and cross-validation (Table 5), the resultant models were selected to map AGB. The cross-validation point distributions for these models are shown in Figure 10. The derivative-based model was applied to herbaceous pixels in the AVIRIS-NG and UAVSAR products. The same process was performed on forest pixels using the reflectance PLS x-scores, volume, and double bounce model. Combined with the classification map of WLD herbaceous and forested wetland vegetation generated from the AVIRIS-NG data (Figure 8), the models produced the AGB map in Figure 11. 
Table 4. Model performance statistics.

\begin{tabular}{|c|c|c|c|c|c|c|c|c|c|c|c|c|}
\hline & \multicolumn{6}{|c|}{$\begin{array}{l}\text { Herbaceous AGB Models } \\
\left(\mathrm{n}=25, \text { mean }=359.24 \mathrm{~g} / \mathrm{m}^{2}\right)\end{array}$} & \multicolumn{6}{|c|}{$\begin{array}{c}\text { Forest AGB Models } \\
\left(\mathrm{n}=36, \text { mean }=25,555 \mathrm{~g} / \mathrm{m}^{2}\right)\end{array}$} \\
\hline & $\begin{array}{l}\text { PLS } \\
\text { Comps }\end{array}$ & $\mathbf{R}^{2}$ & RMSE & MAE & AIC & $\mathbf{p}$ & $\begin{array}{l}\text { PLS } \\
\text { Comps }\end{array}$ & $\mathbf{R}^{2}$ & RMSE & MAE & AIC & p \\
\hline 1. NDVI & & 0.08 & 150.59 & 111.38 & 325.68 & 0.18 & & 0.08 & 16,309 & 13,033 & 805 & 0.11 \\
\hline 2. Reflectance PLSR & 3 & 0.33 & 180.51 & 92.21 & & & 4 & 0.45 & 20,418 & 9974 & & \\
\hline 3. First Derivative PLSR & 2 & 0.46 & 189.62 & 81.65 & & & 2 & 0.35 & 19,708 & 11,260 & & \\
\hline 4. HV Backscatter & & 0.01 & 156.06 & 108.04 & 327.46 & 0.65 & & 0.01 & 16,874 & 14,248 & 803 & 0.05 \\
\hline 5. Volume, Double Bounce Components & & 0.08 & 150.58 & 100.85 & 327.67 & 0.41 & & 0.35 & 13,706 & 11,409 & 794 & $<0.01$ \\
\hline 6. NDVI, HV Backscatter & & 0.08 & 150.42 & 110.79 & 327.62 & 0.40 & & 0.09 & 16,138 & 13,007 & 806 & 0.19 \\
\hline 7. NDVI, Volume, Double Bounce & & 0.23 & 137.22 & 99.91 & 325.03 & 0.13 & & 0.38 & 13,375 & 10,972 & 794 & $<0.01$ \\
\hline 8. Reflectance PLS X-Scores, HV Backscatter & 3 & 0.41 & 120.25 & 89.51 & 320.43 & 0.03 & 4 & 0.45 & 12,583 & 9979 & 794 & $<0.01$ \\
\hline 9. Derivative PLS X-Scores, HV Backscatter & 2 & 0.51 & 109.24 * & 79.44 & 313.63 * & $<0.01$ & 2 & 0.36 & 13,560 & 11,311 & 795 & $<0.01$ \\
\hline 10. Reflectance PLS X-Scores, Volume, Double & 3 & 0.42 & 117.73 & 86.99 & 322.21 & 0.05 & 4 & 0.53 * & 11,626 * & 8489 * & $790 *$ & $<0.01$ \\
\hline 11. Derivative PLS X-Scores, Volume, Double Bounce & 2 & $0.51 *$ & 110.10 & $77.07 *$ & 316.02 & $<0.01$ & 2 & 0.48 & 12,233 & 10,066 & $790 *$ & $<0.01$ \\
\hline
\end{tabular}

Table 5. Mean absolute error results from cross-validation for applicable models.

\begin{tabular}{|c|c|c|}
\hline & $\begin{array}{c}\text { Herbaceous MAE } \\
\left(\mathrm{g} / \mathrm{m}^{2}\right)\end{array}$ & $\begin{array}{l}\text { Forest MAE } \\
\left(\mathrm{g} / \mathrm{m}^{2}\right)\end{array}$ \\
\hline 2. Reflectance PLSR & 112.57 & 12,061 \\
\hline 3. First derivative PLSR & 110.05 & 14,192 \\
\hline 4. HV backscatter & 114.71 & 16,481 \\
\hline 5. Volume, double bounce components & 111.71 & 12,477 \\
\hline 7. NDVI, volume, double bounce components & 118.35 & 12,040 \\
\hline 8. Reflectance PLS X-scores, HV backscatter & 114.67 & 12,346 \\
\hline 9. Derivative PLS X-scores, HV backscatter & 110.47 & 14,345 \\
\hline 10. Reflectance PLS X-scores, volume, double bounce & 114.43 & 11,060 * \\
\hline 11. Derivative PLS X-scores, volume, double bounce & $106.38 *$ & 12,950 \\
\hline
\end{tabular}

* Marked values indicate the lowest MAE results, and thus the selected models. Models 1 (NDVI) and 6 (NDVI, HV Backscatter) are excluded as performance was not significant ( $\mathrm{p}<0.05$ ) for either herbaceous or forested vegetation. 


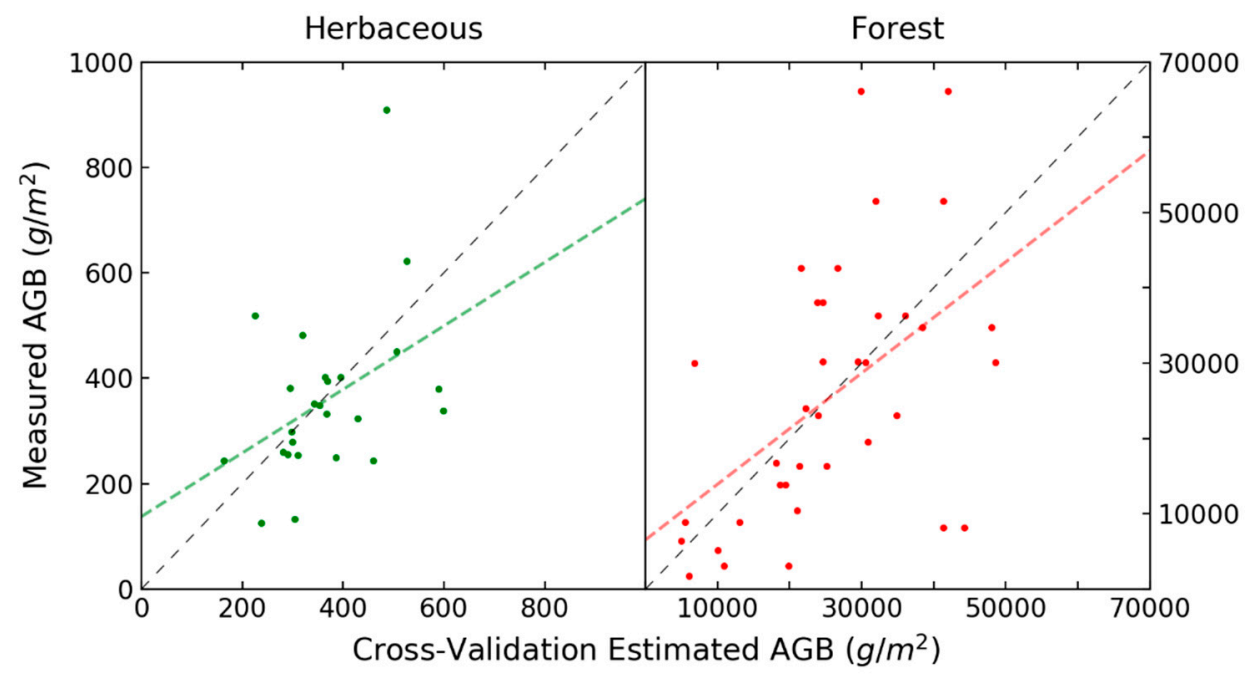

Figure 10. Point distribution of cross-validation predictions vs. sample AGB values for the herbaceous (model 11) and forest (model 10) models using the PLS x-scores. The black dashed lines represent the 1:1 line while the green and red dashed lines represent the lines of best fit for the cross-validation predictions, and thus the potential model biases.

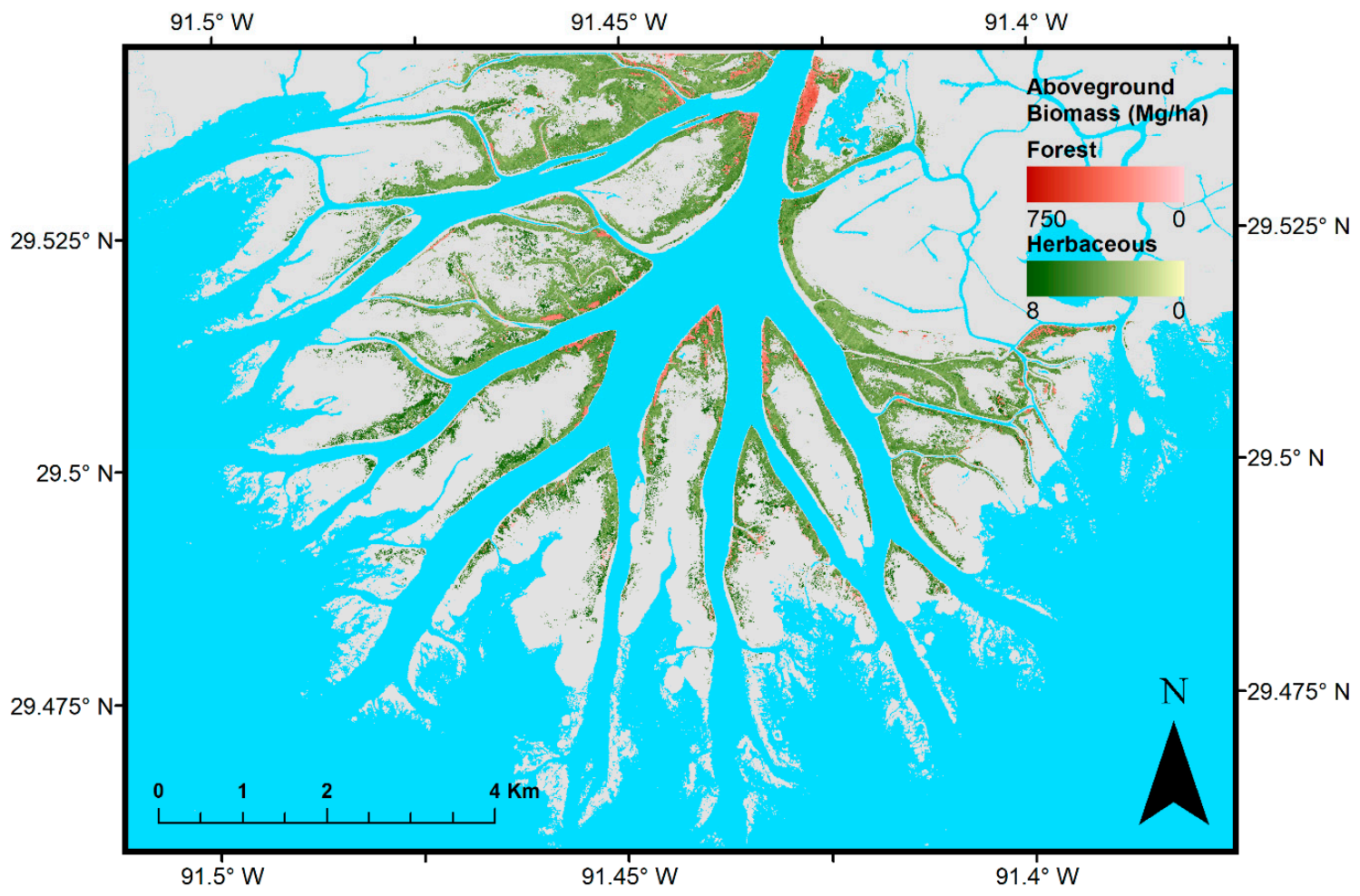

Figure 11. Estimated aboveground biomass $(\mathrm{Mg} / \mathrm{ha})$ map of herbaceous and forested wetland vegetation in the WLD. The gray area represents $N$. lutea, floating vegetation, and submerged aquatic vegetation that was not included in this analysis.

\section{Discussion}

The VIP response calculated simultaneously with the PLSR models offers insight into the spectral properties inherent to each model. Using a threshold of VIP $>1$, Figures 5 and 6 highlight the spectral domains that most increase the reflectance and derivative PLSR models' respective predictive capacity. The herbaceous reflectance model is particularly sensitive to the NIR domain, while the forest reflectance model is sensitive to the visible, red edge, parts of the NIR, and SWIR 1 (1493.37-1778.87 nm) 
domains. For the forest reflectance model, the visible, red edge, and NIR bands associated with high VIP correspond with negative model coefficients, though much of the NIR domain exhibits positive coefficients and VIP values close to one. Turgid leaves, i.e., the leaf canopy, is associated with visible absorption (with relatively higher green reflectance) and NIR reflectance [64]. Thus, the importance of these bands indicates that greater scattering from leaves is closely associated with greater forest biomass. The SWIR 1 region also exhibits high VIP values and positive coefficients. This spectral domain responds to non-photosynthetic vegetation (NPV), such that woody stems show low reflectance variation relative to the NIR domain $[64,65]$. The observed significance and positive coefficient values across the SWIR 1 domain likely indicate that more observed NPV material is associated with higher tree biomass. It is likely that this is due to lower canopy closure and leaf content being observed by AVIRIS-NG.

Conversely, the derivative-based PLSR models are attuned to specific spectral features' characteristics. Both the herbaceous and forest PLSR model VIP scores depict a significant response to the red edge region (Figure 6), for which the steepness and magnitude are strongly associated with red-absorbing chlorophyll and other pigments [65-67]. The other important regions in both models represent spectral features whose depth and curvature are associated with leaf water content $[65,68,69]$. It should be noted that the herbaceous derivative PLSR model quantifies a narrow feature at approximately $810-820 \mathrm{~nm}$ as important (Figure 6). It is unclear whether this feature is an artifact of the minor water vapor absorption lines from 813 to 820 [70], or whether it is correlated with a particular biophysical property in the herbaceous canopy [71]. For example, narrowband reflectance at $810 \mathrm{~nm}$ has been applied for estimating chlorophyll content [66,72], water stress [65], nutrient (nitrogen, phosphorous, potassium)-related stress [73], and photosynthetic rate [74]. Additionally, reflectance at $820 \mathrm{~nm}$ has been incorporated in indices for detecting plant water stress [68] or leaf water content while accounting for chlorophyll concentrations and structural properties [75]. Given the water vapor absorption feature here and the numerous studies that use its wavelength range for detecting plant stress, the spectral response may be affected by the canopy liquid water features-which correlates with biomass - in turn affecting atmospheric reflectance estimates. Whereas the reflectance-based models describe biomass as a function of canopy cover, the first-derivative of the reflectance spectra train the models on chlorophyll and water absorption features. In forested wetlands where reflectance is the superior predictor, leaf abundance and woody NPV appear to be most closely associated with AGB. For herbaceous vegetation, water content appears to be most closely related to AGB.

For each of these PLSR models, the PLS x-scores values entail the essential information, though not the full weighted projection for each input band. Carrying the PLS x-scores forward into the integrated OLSR models complements the biochemical information inherent in the spectra with the structural information in the SAR data. For these data, model results including $\mathrm{R}^{2}$, error metrics, and AIC values (Table 4) indicate that full spectral responses are more effective at estimating AGB than standard vegetation indices. With respect to optical remote sensing generally, this supports the superior efficacy of imaging spectrometers over multispectral instruments. It is important to determine whether these optical data, being sensitive to vegetation biochemical information, aptly complement the information provided by the interaction of radar signals with plant structure.

The HV backscatter data from UAVSAR alone shows no significant relationship with AGB in either plant type in this assessment, though this parameter has proven effective in other AGB retrievals [25,48,52]. It should be noted that HV backscatter constitutes the volume scattering component in the Freeman-Durden algorithm [51]. When the Freeman-Durden polarimetric decomposition is applied to the UAVSAR data, though, the scattering components together in forested wetlands show a weak but significant $\left(\mathrm{R}^{2}=0.35, \mathrm{p}<0.01\right)$ relationship with AGB. On the contrary, the volume and double bounce scattering model remains insignificant for herbaceous vegetation-on par with the HV backscatter model. As HV backscatter is essentially equal to the volume scattering, any improvement from the addition of the double bounce component is due to the quantification of corner reflection and its interaction with the volume scattering variable. From this we can conclude that the polarimetric 
decomposition significantly increases AGB estimation capability for forest vegetation but not for herbaceous vegetation, as the volume and double bounce scattering components are controlled by plant structures (i.e., leaf canopy and tree trunks) that are more differentiated among trees.

A similar pattern is manifest in the combination of the SAR data with the PLS x-scores. Adding NDVI to any of the SAR-dominated models does not add any significant explanatory power, though the PLS $x$-scores combined with SAR data increase performance across the board. NDVI, showing little explanatory power alone or with other variables, here represents a standard multispectral application and the first step in a series of increasingly complicated empirical models. For herbaceous vegetation, HV backscatter with the PLS $x$-scores produces the lowest AIC, which quantifies model quality in terms of accuracy, variable explanatory power, and model simplicity. However, the PLS x-scores combined with the Freeman-Durden components produced the lowest model (Table 4) and cross-validation (Table 5) error values. Whereas the lower error is desirable for maximizing AGB estimation accuracy, the marginal increase in performance with the polarimetric decomposition may be less preferable than a simpler model requiring less data processing in studies looking solely at herbaceous vegetation. The forested wetland vegetation, though, shows a significant decrease in error with the inclusion of the Freeman-Durden components. Coupling the PLS x-scores with the scattering components here produces a significant reduction in cross-validation error as well as the lowest AIC value. We conclude that while the polarimetric decomposition only slightly increases herbaceous AGB estimation accuracy when paired with imaging spectrometer data, it enables a significant increase in model performance for forested vegetation.

Lastly, we provide AGB estimates for the study domain over the WLD. $9.92 \mathrm{~km}^{2}$ of herbaceous emergent vegetation was mapped, over which we calculated a mean AGB of $3.58 \mathrm{Mg} / \mathrm{ha}$ and a total of $3551.31 \mathrm{Mg}$. For the $0.93 \mathrm{~km}^{2}$ of forested wetland vegetation, we estimated a mean AGB of $294.78 \mathrm{Mg} / \mathrm{ha}$ and a total of $27,499.14 \mathrm{Mg}$.

Other studies have assessed AGB in the broader MDP [6,29], including the Atchafalaya basin, though these studies employ coarser satellite data that is not as well suited for local-scale sites such as the WLD. For example, Byrd et al. [29] use Landsat and Sentinel-1 data to model herbaceous marsh biomass in seven coastal wetland regions throughout the conterminous United States, of which the MDP is one. An expansive in situ dataset was paired with six Landsat indices in a random forest model to estimate AGB, and subsequently uses an average percent carbon value of $44.1 \%$ to calculate an average carbon concentration of $1.85 \mathrm{Mg} / \mathrm{ha}$ in coastal Louisiana. This yields a mean herbaceous AGB value of $4.20 \mathrm{Mg} / \mathrm{ha}$ throughout the greater MDP, higher than this study's predicted average. This may be due to the study's use of coarser Landsat data, whose larger pixels likely mixed some forested wetlands with the herbaceous cover. Further, the study [25] is not limited to emergent vegetation and includes the deltaic island interiors (i.e., interdistributary bays) where floating vegetation is prominent, which may appear very bright in optical data (Figure 1) and lead to erroneous higher AGB estimates. In addition, Thomas et al. [6] use an in situ AGB dataset for both herbaceous and forested wetland vegetation in the study area, which overlaps with the data used in this study, reporting a mean sample AGB density of $3.82 \mathrm{Mg} / \mathrm{ha}$ for herbaceous wetlands and $227.02 \mathrm{Mg} / \mathrm{ha}$ for forested wetlands in May of 2015. Thomas et al. [6], however, could not devise a robust model from coincident Sentinel-1 and Sentinel-2 data with the number of field sites available. This corroborates this study's poor results from NDVI and HV backscatter-only models, which represent standard multispectral and backscatter methods typically employed with widely available satellite data products. This further indicates that imaging spectrometers, especially in combination with SAR, have greater potential for AGB estimation than currently available multispectral instruments. Our lower herbaceous AGB estimates compared to these studies [6,29] are likely due to the more limited dataset not including many of the higher biomass samples from the peak growing season in September as they were not coincident with remotely sensed imagery. Additionally, with the October flight campaign being just after the peak biomass period, some of the herbaceous species had started to senesce, likely resulting in lower AGB estimates. Unlike these studies $[6,29]$, where coarser satellite-based data is used to map vegetation, here we employ 
high-resolution remote sensing data to map AGB at a local scale. This enables our estimates to be used in future studies concerning AGB's relationships with elevation, age, and species.

\section{Conclusions}

This study integrated airborne imaging spectrometer and SAR data for estimating wetland vegetation AGB, and in doing so showed that these distinct datasets complement each other and enable more accurate models than either sensor alone. Additionally, the full spectral response provided by the imaging spectrometer was shown to be superior to standard univariate vegetation index approaches for AGB estimation. Building on this, we found that the first derivative of reflectance is superior to reflectance itself for estimating AGB in herbaceous vegetation, though the converse holds true for forested vegetation. We have identified the spectral regions most closely associated with AGB, which predominately relate to chlorophyll and water content in herbaceous vegetation as well as leaf abundance and NPV in forested wetlands. Similarly, the use of a polarimetric decomposition for the SAR data increases the models' effectiveness relative to standard backscatter, and this increase is larger for forested vegetation than for herbaceous due to greater structural diversity. These factors lead the integrated multi-sensor models to attain superior accuracies. High resolution imaging spectrometer data is shown here to be an effective tool for modeling and mapping AGB when integrating the structural information provided by SAR. Our approach and local AGB estimates, which are lower on average than other remote sensing studies in coastal Louisiana [6,29], are suited for further study of AGB's ecological role in deltaic emergent wetland development.

Our methods and findings bear significance for future studies and Earth-observing satellite missions. Further study should incorporate more herbaceous and forested wetland AGB data coincident with field spectrometer/imaging spectrometer and SAR data collections. In doing so, the spectral characteristics associated with AGB across different vegetation types may be more accurately quantified and a transferable algorithm for emergent wetland vegetation may be developed. Our analysis provides an assessment of capabilities for two upcoming spaceborne missions: the NASA ISRO Synthetic Aperture Radar (NISAR), an L-band sensor partly designed to estimate biomass, and the Surface Biology and Geology (SBG) mission that will provide frequent and global hyperspectral data akin to AVIRIS-NG. Our methods show the benefit of leveraging and integrating imaging spectrometer and radar data to estimate wetland vegetation biomass.

Author Contributions: Conceptualization, D.J., M.S., K.C.C., and R.R.T.; methodology, D.J.; software, D.J.; validation, D.J., K.C.C., and G.S.O.; formal analysis, D.J., K.C.C., G.S.O., E.C.-M., and A.M., investigation, D.J., M.S., E.C.-M., A.M., and R.R.T.; resources, D.J., M.S., K.C.C., and R.R.T.; data curation, D.J., M.S., K.C.C., E.C.-M., A.M., and R.R.T.; writing—original draft preparation, D.J., writing—review and editing, D.J., M.S., K.C.C., G.S.O., E.C.-M., A.M., and R.R.T.; visualization, D.J., K.C.C., and G.S.O.; supervision, D.J., M.S., K.C.C., G.S.O. and R.R.T.; project administration, D.J., M.S., K.C.C., and R.R.T.; funding acquisition, D.J., M.S., K.C.C., and R.R.T.

Funding: This research was funded in part by the NASA Earth and Space Sciences Fellowship and Carbon Monitoring System program, grant \#105357-613570.02.03.02.09.

Acknowledgments: Research was carried out at the Jet Propulsion Laboratory, California Institute of Technology, under a contract with the National Aeronautics and Space Administration (80NM0018D0004). This study was performed within the NASA Carbon Monitoring System and the Terrestrial Ecology Program. Field work benefited from projects supported by the National Science Foundation via the National Center for Earth-Surface Dynamics (EAR-0120914), Frontiers of Earth Surface Dynamics (FESD, OCE-1135427), and the Coastal SEES program at LSU (EAR-1427389). This study further benefited from the Coastwide Reference Monitoring System (CRMS) Program's long-term monitoring network, funded by the Coastal Wetland Planning, Protection, and Restoration Act Program and the State of Louisiana. We would like to thank the landowners who permitted access to their properties for this research, including Louisiana Department of Wildlife and Fisheries, Apache Corporation, ConocoPhillips, Continental Land and Fur, Emerald Land Corporation, Gruy Petroleum, Harry Bourg Corporation, and Miami Corporation. Additional thanks to Sarai Piazza and Leigh Anne Sharp for providing technical guidance in accessing CRMS stations and landowner properties. Lastly, we would like to thank Alexandra Christensen for field assistance and logistical support (C) 2019. All rights reserved.

Conflicts of Interest: The authors declare no conflict of interest. 


\section{Appendix A}

Table A1. Herbaceous wetland aboveground biomass field sample data.

\begin{tabular}{cccccc}
\hline Collection Date & Plot Size $\left.\mathbf{( m}^{\mathbf{2}}\right)$ & Latitude & Longitude & Dominant Species & AGB $\left(\mathbf{g} / \mathbf{m}^{\mathbf{2}}\right)$ \\
\hline 6 May 2015 & 0.25 & 29.53893 & -91.38042 & Sagittaria lancifolia & 324.10 \\
6 May 2015 & 0.25 & 29.53918 & -91.38051 & Sagittaria lancifolia & 401.52 \\
6 May 2015 & 0.25 & 29.53943 & -91.38044 & Sagittaria lancifolia & 394.42 \\
8 May 2015 & 0.25 & 29.42521 & -91.27973 & Alternanthera philoxeroides & 132.92 \\
8 May 2015 & 0.25 & 29.47480 & -91.10216 & Spartina alterniflora & 332.30 \\
8 May 2015 & 0.25 & 29.42525 & -91.27923 & Ludwigia grandiflora & 259.50 \\
8 May 2015 & 0.25 & 29.42533 & -91.27925 & Typha domingensis & 299.20 \\
8 May 2015 & 0.25 & 29.42527 & -91.27888 & Typha domingensis & 519.10 \\
8 May 2015 & 0.25 & 29.42527 & -91.27280 & Colocasia esculenta & 244.44 \\
8 May 2015 & 0.25 & 29.50637 & -91.23360 & Saururus cernuus & 126.00 \\
9 May 2015 & 0.25 & 29.41716 & -90.94989 & Sagittaria lancifolia & 451.28 \\
9 May 2015 & 0.25 & 29.41719 & -90.94984 & Eleocharis radicans & 338.00 \\
9 May 2015 & 0.25 & 29.41759 & -90.95010 & Sagittaria lancifolia & 908.76 \\
9 May 2015 & 0.25 & 29.41762 & -90.95002 & Sagittaria lancifolia & 622.20 \\
9 May 2015 & 0.25 & 29.41796 & -90.95036 & Sagittaria lancifolia & 379.44 \\
15 November 2016 & 0.25 & 29.50650 & -91.44556 & Colocasia esculenta & 250.04 \\
15 November 2016 & 0.25 & 29.50644 & -91.44558 & Colocasia esculenta & 351.44 \\
15 November 2016 & 0.25 & 29.50639 & -91.44567 & Colocasia esculenta & 253.72 \\
15 November 2016 & 0.25 & 29.50672 & -91.44564 & Colocasia esculenta & 243.32 \\
15 November 2016 & 0.25 & 29.50664 & -91.44550 & Colocasia esculenta & 279.68 \\
15 November 2016 & 0.49 & 29.50664 & -91.44539 & Colocasia esculenta & 482.02 \\
15 November 2016 & 0.49 & 29.50656 & -91.44542 & Colocasia esculenta & 348.67 \\
15 November 2016 & 0.75 & 29.50639 & -91.44541 & Colocasia esculenta & 255.73 \\
15 November 2016 & 0.75 & 29.50647 & -91.44531 & Colocasia esculenta & 380.67 \\
15 November 2016 & 0.75 & 29.50655 & -91.44576 & Colocasia esculenta & 402.40 \\
\hline
\end{tabular}

Table A2. Forested wetland aboveground biomass field sample data.

\begin{tabular}{cccccc}
\hline Collection Date & Plot Radius $(\mathbf{m})$ & Latitude & Longitude & Dominant Species & AGB $\left(\mathbf{g} / \mathbf{m}^{\mathbf{2}}\right)$ \\
\hline 6-8 May 2015 & 10 & 29.51538 & -91.43171 & Salix nigra & 38,030 \\
6-8 May 2015 & 10 & 29.51121 & -91.43267 & Salix nigra & 8160 \\
6-8 May 2015 & 10 & 29.51070 & -91.42787 & Salix nigra & 42,590 \\
6-8 May 2015 & 10 & 29.50545 & -91.43219 & Salix nigra & 30,100 \\
6-8 May 2015 & 10 & 29.61462 & -91.32393 & Taxodium distichum & 19,552 \\
6-8 May 2015 & 10 & 29.49074 & -91.43710 & Salix nigra & 8850 \\
6-8 May 2015 & 10 & 29.61431 & -91.32350 & Salix nigra & 1790 \\
6-8 May 2015 & 10 & 29.51413 & -91.43279 & Salix nigra & 51,520 \\
6-8 May 2015 & 10 & 29.51214 & -91.43756 & Salix nigra & 23,100 \\
6-8 May 2015 & 10 & 29.51361 & -91.44246 & Salix nigra & 16,350 \\
6-8 May 2015 & 10 & 29.51607 & -91.45768 & Salix nigra & 13.830 \\
6-8 May 2015 & 10 & 29.51266 & -91.45770 & Salix nigra & 30,210 \\
6-8 May 2015 & 10 & 29.50539 & -91.44698 & Salix nigra & 3070 \\
6-8 May 2015 & 10 & 29.53821 & -91.44451 & Salix nigra & 36,300 \\
6-8 May 2015 & 10 & 29.53608 & -91.43400 & Salix nigra & 66,080 \\
6-8 May 2015 & 10 & 29.53263 & -91.43570 & Salix nigra & 34,780 \\
6-8 May 2015 & 10 & 29.50715 & -91.44643 & Salix nigra & 5180 \\
6-8 May 2015 & 10 & 29.53821 & -91.44451 & Salix nigra & 36,300 \\
6-8 May 2015 & 10 & 29.53608 & -91.43400 & Salix nigra & 66,080 \\
6-8 May 2015 & 10 & 29.53263 & -91.43570 & Salix nigra & 34,780 \\
6-8 May 2015 & 10 & 29.51538 & -91.43171 & Salix nigra & 38,030 \\
6-8 May 2015 & 10 & 29.51413 & -91.43279 & Salix nigra & 51,520 \\
6-8 May 2015 & 10 & 29.51121 & -91.43267 & Salix nigra & 8160 \\
6-8 May 2015 & 10 & 29.51070 & -91.42787 & Salix nigra & 42,590 \\
6-8 May 2015 & 10 & 29.51214 & -91.43756 & Salix nigra & 23,100 \\
\hline
\end{tabular}


Table A2. Cont.

\begin{tabular}{cccccc}
\hline Collection Date & Plot Radius $(\mathbf{m})$ & Latitude & Longitude & Dominant Species & AGB $\left(\mathbf{g} / \mathbf{m}^{\mathbf{2}}\right)$ \\
\hline 6-8 May 2015 & 10 & 29.51361 & -91.44246 & Salix nigra & 16,350 \\
6-8 May 2015 & 10 & 29.51607 & -91.45768 & Salix nigra & 13,830 \\
6-8 May 2015 & 10 & 29.51299 & -91.45649 & Salix nigra & 16,710 \\
6-8 May 2015 & 10 & 29.52044 & -91.44769 & Salix nigra & 29,990 \\
6-8 May 2015 & 10 & 29.49821 & -91.45908 & Salix nigra & 24,020 \\
6-8 May 2015 & 10 & 29.51266 & -91.45770 & Salix nigra & 30,210 \\
6-8 May 2015 & 10 & 29.50545 & -91.43219 & Salix nigra & 30,100 \\
6-8 May 2015 & 10 & 29.50539 & -91.44698 & Salix nigra & 3070 \\
6-8 May 2015 & 10 & 29.49074 & -91.43710 & Salix nigra & 8850 \\
6-8 May 2015 & 10 & 29.48458 & -91.43940 & Salix nigra & 10,430 \\
6-8 May 2015 & 10 & 29.51120 & -91.44429 & Salix nigra & 6370 \\
\hline
\end{tabular}

Table A3. Aboveground biomass ordinary least squares regression models.

\begin{tabular}{ccc}
\hline & $\begin{array}{c}\text { Herbaceous } \\
\text { Model Coefficient }\end{array}$ & $\begin{array}{c}\text { Forest } \\
\text { Model Coefficient }\end{array}$ \\
\hline Derivative PLS Component 1 & -1966.287 & \\
Derivative PLS Component 2 & -11555.016 & 1188.786 \\
Reflectance PLS Component 1 & & $-16,737.491$ \\
Reflectance PLS Component 2 & & $-194,039.813$ \\
Reflectance PLS Component 3 & & $-41,831.015$ \\
Reflectance PLS Component 4 & -7.293 & 1471.021 \\
Volume Scattering Component & 3.418 & -1398.494 \\
Double Bounce Scattering & 339.758 & $23,568.644$ \\
Component & Constant &
\end{tabular}

Volume and double bounce scattering component values are inherently negative. The coefficient sign is indicative of an inverse relationship if positive or a positive relationship if negative.

\section{References}

1. Zhang, M.; Ustin, S.L.; Rejmankova, E.; Sanderson, E.W. Monitoring Pacific Coast Salt Marshes Using Remote Sensing. Ecol. Appl. 1997, 7, 1039-1053. [CrossRef]

2. Morris, J.T.; Sundareshwar, P.V.; Nietch, C.T.; Kjerfve, B.; Cahoon, D.R. Responses of Coastal Wetlands to Rising Sea Level. Ecology 2002, 83, 2869-2877. [CrossRef]

3. Mudd, S.M.; Howell, S.M.; Morris, J.T. Impact of dynamic feedbacks between sedimentation, sea-level rise, and biomass production on near-surface marsh stratigraphy and carbon accumulation. Estuar. Coast. Shelf Sci. 2009, 82, 377-389. [CrossRef]

4. Adam, E.; Mutanga, O.; Rugege, D. Multispectral and hyperspectral remote sensing for identification and mapping of wetland vegetation: A review. Wetl. Ecol. Manag. 2010, 18, 281-296. [CrossRef]

5. Byrd, K.B.; O'Connell, J.L.; Di Tommaso, S.; Kelly, M. Evaluation of sensor types and environmental controls on mapping biomass of coastal marsh emergent vegetation. Remote Sens. Environ. 2014, 149, 166-180. [CrossRef]

6. Thomas, N.; Simard, M.; Cateñeda-Moya, E.; Byrd, K.; Windham-Myers, L.; Bevington, A.; Twilley, R.R. High-resolution mapping of biomass and distribution of marsh and forested wetlands in southeastern coastal Louisiana. Int. J. Appl. Earth Obs. Geoinf. 2019, 80, 257-267. [CrossRef]

7. Craft, C.; Clough, J.; Ehman, J.; Jove, S.; Park, R.; Pennings, S.; Guo, H.; Machmuller, M. Forecasting the effects of accelerated sea-level rise on tidal marsh ecosystem services. Front. Ecol. Environ. 2009, 7, 73-78. [CrossRef]

8. Kirwan, M.L.; Guntenspergen, G.R. Influence of tidal range on the stability of coastal marshland. J. Geophys. Res. 2010, 115, 1-11. [CrossRef]

9. Turpie, K.R.; Klemas, V.V.; Byrd, K.; Kelly, M.; Jo, Y.H. Prospective HyspIRI global observations of tidal wetlands. Remote Sens. Environ. 2015, 167, 206-217. [CrossRef] 
10. Schile, L.M.; Callaway, J.C.; Morris, J.T.; Stralberg, D.; Thomas Parker, V.; Kelly, M. Modeling tidal marsh distribution with sea-level rise: Evaluating the role of vegetation, sediment, and upland habitat in marsh resiliency. PLoS ONE 2014, 9, e88760. [CrossRef]

11. Rouse, J.W.; Hass, R.H.; Schell, J.A.; Deering, D.W. Monitoring vegetation systems in the great plains with ERTS. In Proceedings of the Third Earth Resources Technology Satellite (ERTS) Symposium, Washington, DC, 10-14 December 1973; Volume 1, pp. 309-317.

12. Li, X.; Gar-On Yeh, A.; Wang, S.; Liu, K.; Liu, X.; Qian, J.; Chen, X. Regression and analytical models for estimating mangrove wetland biomass in South China using Radarsat images. Int. J. Remote Sens. 2007, 28, 5567-5582. [CrossRef]

13. Klemas, V. Remote Sensing of Coastal Wetland Biomass: An Overview. J. Coast. Res. 2013, 290, $1016-1028$. [CrossRef]

14. Hong, S.H.; Wdowinski, S. Double-bounce component in cross-polarimetric SAR from a new scattering target decomposition. IEEE Trans. Geosci. Remote Sens. 2014, 52, 3039-3051. [CrossRef]

15. Elvidge, C.D.; Chen, Z. Comparison of broad-band and narrow-band red and near-infrared vegetation indices. Remote Sens. Environ. 1995, 54, 38-48. [CrossRef]

16. Townsend, P.A.; Foster, J.R.; Chastian, R.A., Jr.; Currie, W.S. Canopy nitrogen in the forests of the Central Appalachian Mountains using Hyperion and AVIRIS. IEEE Trans. Geosci. Remote Sens. 2003, 41, 1347-1354. [CrossRef]

17. Townsend, P.A.; Serbin, S.P.; Kruger, E.L.; Gamon, J.A. Disentangling the contribution of biological and physical properties of leaves and canopies in imaging spectroscopy data. Proc. Natl. Acad. Sci. USA 2013, 110, E1074. [CrossRef]

18. Cho, M.A.; Skidmore, A.; Corsi, F.; van Wieren, S.E.; Sobhan, I. Estimation of green grass/herb biomass from airborne hyperspectral imagery using spectral indices and partial least squares regression. Int. J. Appl. Earth Obs. Geoinf. 2007, 9, 414-424. [CrossRef]

19. Tsai, F.; Philpot, W. Derivative analysis of hyperspectral data. Remote Sens. Environ. 1998, 66, 41-51. [CrossRef]

20. Henderson, F.M.; Lewis, A.J. Radar detection of wetland ecosystems: A review. Int. J. Remote Sens. 2008, 29, 5809-5835. [CrossRef]

21. Treuhaft, R.N.; Asner, G.P.; Law, B.E. Structure-based forest biomass from fusion of radar and hyperspectral observations. Geophys. Res. Lett. 2003, 30, 1472. [CrossRef]

22. Wang, C.; Wu, J.; Zhang, Y.; Pan, G.; Qi, J.; Sales, W.A. Characterizing L-band scattering of paddy rice in southeast china with radiative transfer model and multitemporal ALOS/PALSAR imagery. IEEE Trans. Geosci. Remote Sens. 2009, 47, 988-998. [CrossRef]

23. Manninen, T.; Stenberg, P.; Rautiainen, M.; Voipio, P.; Smolander, H. Leaf area index estimation of boreal forest using ENVISAT ASAR. IEEE Trans. Geosci. Remote Sens. 2005, 43, 2627-2635. [CrossRef]

24. Ramsey, E.; Rangoonwala, A.; Jones, C.E. Structural classification of marshes with polarimetric SAR highlighting the temporal mapping of marshes exposed to oil. Remote Sens. 2015, 7, 11295-11321. [CrossRef]

25. Neumann, M.; Saatchi, S.S.; Ulander, L.M.H.; Fransson, J.E.S. Assessing performance of L- and P-band polarimetric interferometric SAR data in estimating boreal forest above-ground biomass. IEEE Trans. Geosci. Remote Sens. 2012, 50, 714-726. [CrossRef]

26. Rosen, P.A.; Hensley, S.; Joughin, I.R.; Li, F.K.; Madsen, S.N.; Rodriguez, E.; Goldstein, R.M. Synthetic Aperture Radar Interferometry. Proc. IEEE 2000, 88, 333-382. [CrossRef]

27. Mohammadimanesh, F.; Salehi, B.; Mahdianpari, M.; Brisco, B.; Motagh, M. Wetland Water Level Monitoring Using Interferometric Synthetic Aperture Radar (InSAR): A Review. Can. J. Remote Sens. 2018, 44, 247-262. [CrossRef]

28. Sinha, S.; Jeganathan, C.; Sharma, L.K.; Nathawat, M.S. A review of radar remote sensing for biomass estimation. Int. J. Environ. Sci. Technol. 2015, 12, 1779-1792. [CrossRef]

29. Byrd, K.B.; Ballanti, L.; Thomas, N.; Nguyen, D.; Holmquist, J.R.; Simard, M.; Windham-Myers, L. A remote sensing-based model of tidal marsh aboveground carbon stocks for the conterminous United States. ISPRS J. Photogramm. Remote Sens. 2018, 139, 255-271. [CrossRef]

30. Laurin, G.V.; Chen, Q.; Lindsell, J.A.; Coomes, D.A.; Del Frate, F.; Guerriero, L.; Pirotti, F.; Valentini, R. Above ground biomass estimation in an African tropical forest with lidar and hyperspectral data. ISPRS J. Photogramm. Remote Sens. 2004, 89, 49-58. [CrossRef] 
31. Peerbhay, K.Y.; Mutanga, O.; Ismail, R. Commercial tree species discrimination using airborne AISA Eagle hyperspectral imagery and partial least squares discriminant analysis (PLS-DA) in KwaZulu-Natal, South Africa. ISPRS J. Photogramm. Remote Sens. 2013, 79, 19-28. [CrossRef]

32. Twilley, R.R.; Bentley, S.J.; Chen, Q.; Edmonds, D.A.; Hagen, S.C.; Lam, N.S.N.; Willson, C.S.; Xu, K.; Braud, D.; Hampton Peele, R.; et al. Co-evolution of wetland landscapes, flooding, and human settlement in the Mississippi River Delta Plain. Sustain. Sci. 2016, 11, 711-731. [CrossRef] [PubMed]

33. Bevington, A.E.; Twilley, R.R.; Sasser, C.E.; Holm, G.O. Contribution of river floods, hurricanes, and cold fronts to elevation change in a deltaic floodplain, northern Gulf of Mexico, USA. Estuar. Coast. Shelf Sci. 2017, 191, 188-200. [CrossRef]

34. Couvillion, B.R.; Beck, H.; Schoolmaster, D.; Fischer, M. Land Area Change in Coastal Louisiana (1932 to 2010) Map 3381; U.S. Geological Survey: Reston, VA, USA, 2017.

35. Byrd, K.B.; Ballanti, L.; Thomas, N.; Nguyen, D.; Holmquist, J.R.; Simard, M.; Windham-Myers, L. Aboveground Biomass High-Resolution Maps for Selected US Tidal Marshes, 2015; ORNL DAAC: Oak Ridge, TN, USA, 2018. [CrossRef]

36. Shlemon, R.J. Subaqueous delta formation-Atchafalaya Bay, Louisiana. In Deltas: Models for Exploration; Broussard, M.L., Ed.; Houston Geological Society: Houston, TX, USA, 1975; pp. 209-221.

37. Allen, Y.C.; Couvillion, B.R.; Barras, J.A. Using Multitemporal Remote Sensing Imagery and Inundation Measures to Improve Land Change Estimates in Coastal Wetlands. Estuar. Coast. 2012, 35, 190-200. [CrossRef]

38. Steyer, G.D.; Sasser, C.E.; Visser, J.M.; Swenson, E.M.; Nyman, J.A.; Raynie, R.C. A proposed coast-wide reference monitoring system for evaluating wetland restoration trajectories in Louisiana. Environ. Monit. Assess. 2003, 81, 107-117. [CrossRef] [PubMed]

39. Jenkins, J.C.; Chojnacky, D.C.; Heath, L.S.; Birdsey, R.A. National-Scale Biomass Estimators for United States Tree Species. For. Sci. 2003, 49, 12-35.

40. Jenkins, J.C.; Chojnacky, D.C.; Heath, L.S.; Birdsey, R.A. Comprehensive Database of Diameter-based Biomass Regressions for North. American Tree Species; US Department of Agriculture, Forest Service, Northeastern Research Station: Newtown Square, PA, USA, 2004.

41. Chojnacky, D.C.; Heath, L.S.; Jenkins, J.C. Updated generalized biomass equations for North American tree species. Forestry 2013, 87, 129-151. [CrossRef]

42. Hamlin, L.; Green, R.O.; Mouroulis, P.; Eastwood, M.; Wilson, D.; Dudik, M.; Paine, C. Imaging spectrometer science measurements for terrestrial ecology: AVIRIS and new developments. In Proceedings of the 2011 Aerospace Conference, Big Sky, MT, USA, 5-12 March 2011; pp. 1-8.

43. Thompson, D.R.; Gao, B.C.; Green, R.O.; Roberts, D.A.; Dennison, P.E.; Lundeen, S.R. Atmospheric correction for global mapping spectroscopy: ATREM advances for the HyspIRI preparatory campaign. Remote Sens. Environ. 2015, 167, 64-77. [CrossRef]

44. Gao, B.C.; Heidebrecht, K.B.; Goetz, A.F.H. Derivation of scaled surface reflectances from AVIRIS data. Remote Sens. Environ. 1993, 44, 165-178. [CrossRef]

45. Bue, B.D.; Thompson, D.R.; Eastwood, M.; Green, R.O.; Gao, B.C.; Keymeulen, D.; Sarture, C.M.; Mazer, A.S.; Luong, H.H. Real-Time Atmospheric Correction of AVIRIS-NG Imagery. IEEE Trans. Geosci. Remote Sens. 2015, 53, 6419-6428. [CrossRef]

46. Jensen, D.J.; Simard, M.; Cavanaugh, K.C.; Thompson, D.R. Imaging Spectroscopy BRDF Correction for Mapping Louisiana's Coastal Ecosystems. IEEE Trans. Geosci. Remote Sens. 2017, 56, 1739-1748. [CrossRef]

47. Ramsey, E.; Rangoonwala, A.; Chi, Z.; Jones, C.E.; Bannister, T. Marsh Dieback, loss, and recovery mapped with satellite optical, airborne polarimetric radar, and field data. Remote Sens. Environ. 2014, 152, 364-374. [CrossRef]

48. Hamdan, O.; Khali Aziz, H.; Mohd Hasmadi, I. L-band ALOS PALSAR for biomass estimation of Matang Mangroves, Malaysia. Remote Sens. Environ. 2014, 155, 69-78. [CrossRef]

49. Doughty, C.L.; Cavanaugh, K.C. Mapping coastal wetland biomass from high resolution unmanned aerial vehicle (UAV) imagery. Remote Sens. 2019, 11, 540. [CrossRef]

50. Tanase, M.A.; Panciera, R.; Lowell, K.; Tian, S.; Hacker, J.M.; Walker, J.P. Airborne multi-temporal L-band polarimetric SAR data for biomass estimation in semi-arid forests. Remote Sens. Environ. 2014, 145, 93-104. [CrossRef] 
51. Freeman, A.; Durden, S.L. A three-component scattering model for polarimetric SAR data. IEEE Trans. Geosci. Remote Sens. 1998, 36, 963-973. [CrossRef]

52. Mougin, E.; Proisy, C.; Marty, G.; Fromard, F.; Puig, H.; Betoulle, J.L.; Rudant, J.P. Multifrequency and multipolarization radar backscattering from mangrove forests. IEEE Trans. Geosci. Remote Sens. 1999, 37, 94-102. [CrossRef]

53. Farrés, M.; Platikanov, S.; Tsakovski, S.; Tauler, R. Comparison of the variable importance in projection (VIP) and of the selectivity ratio (SR) methods for variable selection and interpretation. J. Chemom. 2015, 29, 528-536. [CrossRef]

54. Mehmood, T.; Liland, K.H.; Snipen, L.; Sæbø, S. A review of variable selection methods in Partial Least Squares Regression. Chemom. Intell. Lab. Syst. 2012, 118, 62-69. [CrossRef]

55. Singer, M.; Krivobokova, T.; Munk, A.; De Groot, B. Partial least squares for dependent data. Biometrika 2016, 103, 351-362. [CrossRef]

56. Chen, S.; Hong, X.; Harris, C.J.; Sharkey, P.M. Sparse Modeling Using Orthogonal Forward Regression with PRESS Statistic and Regularization. IEEE Trans. Syst. Man Cybern. Part B Cybern. 2004, 34, 898-911. [CrossRef]

57. Singh, A.; Serbin, S.P.; McNeil, B.E.; Kingdon, C.C.; Townsend, P.A. Imaging spectroscopy algorithms for mapping canopy foliar chemical and morphological traits and their uncertainties. Ecol. Appl. 2015, 25, 2180-2197. [CrossRef] [PubMed]

58. Jensen, D.; Simard, M.; Cavanaugh, K.; Sheng, Y.; Fichot, C.G.; Pavelsky, T.; Twilley, R. Improving the Transferability of Suspended Solid Estimation in Wetland and Deltaic Waters with an Empirical Hyperspectral Approach. Remote Sens. 2019, 11, 1629. [CrossRef]

59. Sharma, A.; Jacobs, D.W. Bypassing synthesis: PLS for face recognition with pose, low-resolution and sketch. In Proceedings of the CVPR 2011, Providence, RI, USA, 20-25 June 2011; pp. 593-600.

60. Maitra, S.; Yan, J. Principle component analysis and partial least squares: Two dimension reduction techniques for regression. In Applying Multivariate Statistical Models; Casualty Actuarial Society: Arlington County, VA, USA, 2008; pp. 79-90.

61. Delaigle, A.; Hall, P. Methodology and theory for partial least squares applied to functional data. Ann. Stat. 2012, 40, 322-352. [CrossRef]

62. U.S. Geological Survey. USGS NED ned19_n29x75_w091x50_LA-USGS_Atchafalaya2 2012_2014 1/9 arc-Second 2014061515 x 15 Minute IMG; U.S. Geological Survey: Reston, VA, USA, 2014. Available online: http: //ned.usgs.gov/ (accessed on 10 October 2018).

63. Carle, M.V.; Wang, L.; Sasser, C.E. Mapping freshwater marsh species distributions using WorldView-2 high-resolution multispectral satellite imagery. Int. J. Remote Sens. 2014, 35, 4698-4716. [CrossRef]

64. Asner, G.P. Biophysical and biochemical sources of variability in canopy reflectance. Remote Sens. Environ. 1998, 64, 234-253. [CrossRef]

65. Govender, M.; Govender, P.; Weiersbye, I.; Witkowski, E.; Ahmed, F. Review of commonly used remote sensing and ground-based technologies to measure plant water stress. Water SA 2009, 35, 741-752. [CrossRef]

66. Blackburn, G.A. Spectral indices for estimating photosynthetic pigment concentrations: A test using senescent tree leaves. Int. J. Remote Sens. 1998, 19, 657-675. [CrossRef]

67. Blackburn, G.A. Relationships between spectral reflectance and pigment concentrations in stacks of deciduous broadleaves. Remote Sens. Environ. 1999, 70, 224-237. [CrossRef]

68. Lelong, C.C.; Pinet, P.C.; Poilvé, H. Hyperspectral Imaging and Stress Mapping in Agriculture. Remote Sens. Environ. 1998, 66, 179-191. [CrossRef]

69. Champagne, C.M.; Staenz, K.; Bannari, A.; McNairn, H.; Deguise, J.C. Validation of a hyperspectral curve-fitting model for the estimation of plant water content of agricultural canopies. Remote Sens. Environ. 2003, 87, 148-160. [CrossRef]

70. Ponsardin, P.L.; Browell, E.V. Measurements of H216O Linestrengths and Air-Induced Broadenings and Shifts in the 815-nm Spectral Region. J. Mol. Spectrosc. 1997, 185, 58-70. [CrossRef] [PubMed]

71. Ollinger, S.V. Sources of variability in canopy reflectance and the convergent properties of plants. New Phytol. 2010, 189, 375-394. [CrossRef]

72. Gitelson, A.A.; Merzlyak, M.N. Signature analysis of leaf reflectance spectra: Algorithm development for remote sensing of chlorophyll. J. Plant. Physiol. 1996, 148, 494-500. [CrossRef] 
73. Jørgensen, R.N.; Christensen, L.K.; Bro, R. Spectral reflectance at sub-leaf scale including the spatial distribution discriminating NPK stress characteristics in barley using multiway partial least squares regression. Int. J. Remote Sens. 2007, 28, 943-962. [CrossRef]

74. Tian, Y.; Zhu, Y.; Cao, W. Monitoring leaf photosynthesis with canopy spectral reflectance in rice. Photosynthetica 2005, 43, 481-489. [CrossRef]

75. Ceccato, P.; Flasse, S.; Tarantola, S.; Jacquemoud, S.; Grégoire, J.M. Detecting vegetation leaf water content using reflectance in the optical domain. Remote Sens. Environ. 2001, 77, 22-33. [CrossRef]

(C) 2019 by the authors. Licensee MDPI, Basel, Switzerland. This article is an open access article distributed under the terms and conditions of the Creative Commons Attribution (CC BY) license (http://creativecommons.org/licenses/by/4.0/). 